\title{
Aspectos de la dinámica poblacional del lenguado Xystreurys rasile (Jordan, 1890) en el sector del Atlántico Sudoccidental comprendido entre $34^{\circ}$ y $40^{\circ} S^{*}$
}

\author{
Nidia N. Fabré1, María B. Cousseau² y María A. Denegri ${ }^{3}$ \\ ${ }^{1}$ Comisión de Investigación Científica de la Provincia de Buenos Aires (CIC), Instituto Nacional de \\ Investigación y Desarrollo Pesquero (INIDEP), Mar del Plata, Argentina. Domicilio actual: \\ Universidade do Amazonas, ICB, Departamento de Biologia, Manaus, 69083-000. Amazonas, \\ Brasil. E-mail: tchoni1@uol.com.br \\ ${ }^{2}$ Consejo Nacional de Investigaciones Científicas y Técnicas (CONICET), Facultad de Ciencias \\ Exactas y Naturales, Departamento de Ciencias Marinas, Universidad Nacional de Mar del Plata, \\ Dean Funes 3350, 7600 Mar del Plata, Argentina. E-mail: mbcousse@mdp.edu.ar \\ ${ }^{3}$ CONICET, Universidad Nacional del Comahue, 8400 San Carlos de Bariloche, Argentina \\ E-mail: adenegri@crub.uncoma.edu.ar
}

Recibido: 6 noviembre 1998; versión corregida: 20 enero 2001; aceptado: 4 abril 2001

\begin{abstract}
RESUMEN. La estructura poblacional de Xystreurys rasile varía estacionalmente, debido principalmente a la reproducción. Se identificaron grupos segregados por tamaños en el área estudiada $\left(34^{\circ}-40^{\circ} \mathrm{S}\right)$, los ejemplares más pequeños, por lo general, se encontraron en aguas más costeras y al norte, principalmente durante la primavera, y se observó una tendencia de aumento de la longitud media con la latitud. En cuanto a la abundancia, se identificaron dos grupos, uno al norte de los $36^{\circ} \mathrm{S}$ y otro al sur de $\operatorname{los} 37^{\circ} \mathrm{S}$, el primero mucho menos abundante que el segundo. Durante el otoño los especímenes se desplazan hacia aguas más profundas para alimentarse y crecer. En primavera los ejemplares maduros migran hacia la costa y hacia el sur. Tanto el grupo norteño como el sureño, convergen al sur de Mar del Plata $\left(38^{\circ} \mathrm{S}\right)$ para reproducirse. La talla de primera madurez sexual se estimó en $20,0 \mathrm{~cm}$ en los machos y $21,2 \mathrm{~cm}$ en las hembras, con uno y dos años de edad respectivamente. Los adultos se reclutan al área de pesca entre el segundo y tercer año de vida y existen fuertes evidencias que los juveniles no están accesibles a la flota pesquera.
\end{abstract}

Palabras claves: estructura, dinámica poblacional, lenguado, Xystreurys rasile, Atlántico Sudoccidental.

\section{Dynamic population of the flatfish Xystreurys rasile, from the Southwestern Atlantic between $34^{\circ}$ and $40^{\circ} S^{*}$}

\begin{abstract}
The present paper deals with the dynamic population of the flatfish Xystreurys rasile on the Southwest Atlantic between $34^{\circ}$ and $40^{\circ} \mathrm{S}$. Increase of mean size of Xystreurys rasile's shoals was observed to the south. The smallest specimens were found in coastal waters in Spring. Two groups were identified according to the abundance, one northern than $36^{\circ} \mathrm{S}$, characterized with very low captures and the other southern than $37^{\circ} \mathrm{S}$, characterized with higher yields. In Spring mature individuals of $X$. rasile migrate to shallow waters at $38^{\circ} \mathrm{S}$ and southwards for spawning. On the contrary, in autumn they migrate offshore for feeding and growing. First sexual maturity length was estimated in $20.0 \mathrm{~cm}$ for males and $21.2 \mathrm{~cm}$ for females, corresponding to one and two years respectively. Adult recruitment to the fishing area is around the second and third years of age. Strong evidences enforce that juveniles are not available to the fishing fleet.
\end{abstract}

Key words: structure, dynamics population, flatfish, Xystreurys rasile, Southwest Atlantic.

\footnotetext{
* Contribución del Instituto Nacional de Investigación y Desarrollo Pesquero (INIDEP), Argentina, №1189.
} 


\section{INTRODUCCIÓN}

La pesquería de lenguados que desarrolla Argentina está basada en diversas especies, entre las cuales se destaca por su abundancia y amplia distribución Xystreurys rasile (Jordan, 1890) (Fabré y Diaz de Astarloa, 1996). Los lenguados forman parte de la llamada "pesca fina", porque el producto es de alta calidad y las capturas son relativamente pequeñas (alrededor de 8.000 ton en 1997), si se comparan con otros recursos demersales, como la merluza (650.000 ton en 1997).

$\mathrm{Al}$ analizar el promedio de los desembarques de lenguados de los últimos 20 años, se pone de manifiesto que hasta 1984 fue de menos de 3.000 ton y a partir de 1985 los valores ascienden hasta alcanzar cifras entre 7.200 y 10.200 ton anuales (la última cifra corresponde a 1995). Por otra parte, si se toman en cuenta las estimaciones de Captura Máxima Sostenible (CMS), recomendadas para este recurso por el INIDEP (7.379 ton para el período 19861997), parece claro que las capturas de los últimos años no debieran ser superadas.

Regier (1976, en Gulland, 1983), define cinco categorías de recursos pesqueros en un determinado cuerpo de agua o ecosistema, considerando el aprovechamiento de los mismos y el estado de desarrollo de su explotación. La explotación de lenguados por parte de la Argentina puede ser encuadrada, según la clasificación de Regier, como una pesquería intensiva de un recurso lucrativo (MPS: "most profitable stock"), con capturas moderadas a altas. Para este tipo de recurso, según este autor, se requieren estudios sobre dinámica de poblaciones e identificación de las principales interacciones entre los stocks. Sin embargo, el nivel de conocimiento sobre los lenguados es comparable al de una pesquería del tipo exploratoria, o sea, descripciones generales de los principales stocks sobre aspectos como taxonomía y distribución (Cousseau y Diaz de Astarloa 1991; Fabré, 1992; Fabré y Diaz de Astarloa, 1996).

Ante la necesidad de ampliar los conocimientos básicos sobre la biología y dinámica poblacional de lenguados, se realizó el estudio de $X$. rasile, con el objeto de describir la estructura poblacional, determinar posibles variaciones espacio-temporales en dicha estructura y estimar parámetros biológicopesqueros de relevancia en el manejo de la especie. La información está referida al sector del Atlántico Sudoccidental comprendido entre $34^{\circ}$ y $40^{\circ} \mathrm{S}$, en su mayor parte correspondiente a la Zona Común de
Pesca Argentino-Uruguaya. Este trabajo se desarrolló íntegramente en el Instituto Nacional de Investigación y Desarrollo Pesquero (INIDEP), de Mar del Plata, Argentina.

\section{MATERIALES Y MÉTODOS}

\section{Origen de los datos}

Los datos se obtuvieron en campañas demersales realizadas por el INIDEP cuyas referencias se indican en el siguiente cuadro:

\begin{tabular}{|lccc|}
\hline Estación & Fecha & $\begin{array}{c}\mathbf{N}^{\mathbf{0}} \text { de lances } \\
\text { de pesca }\end{array}$ & $\begin{array}{c}\mathbf{N}^{\mathbf{0}} \text { de individuos } \\
\text { capturados }\end{array}$ \\
\hline Otoño & $\begin{array}{c}\text { mayo } \\
\text { de } 1985 \\
\text { mayo de } \\
1986\end{array}$ & 76 & 156 \\
Invierno & $\begin{array}{c}\text { septiembre } \\
\text { de 1986 }\end{array}$ & 75 & 1.291 \\
Primavera & $\begin{array}{c}\text { noviembre } \\
\text { de } 1986 \\
\text { marzo de } \\
\text { Verano }\end{array}$ & 99 & 836 \\
\hline
\end{tabular}

Estas campañas se realizaron para evaluar el recurso merluza y su fauna acompañante en el área comprendida entre los $34^{\circ}$ y $40^{\circ} \mathrm{S}$ y entre los 50 y $400 \mathrm{~m}$ de profundidad. El diseño de muestreo adoptado fue preestratificado al azar, y los estratos se definieron por latitud y profundidad. El área total se dividió en cuadrículas de $4 \mathrm{mn}^{2}$, siendo cada una de éstas una "unidad muestral" = distancia representada por el recorrido del buque en 30' de arrastre a 3,6 nudos. En cada estrato se realizó un número determinado de lances, que dependió de la superficie del estrato y la varianza de la densidad esperada. La ubicación de los lances se determinó al azar, usando una tabla de números aleatorios. Para el presente estudio de $X$. rasile solamente se consideraron los lances de pesca con profundidad entre $50 \mathrm{~m}$ y $100 \mathrm{~m}$, ya que superado este valor no hay registros de la especie (Fabré y Diaz de Astarloa, 1996). Dentro del área total estudiada las capturas de $X$. rasile ocurrieron entre $35^{\circ}$ y $40^{\circ} \mathrm{S}$ y entre los 50 y 90 metros de profundidad, de esta forma se establecieron tres estratos por latitud de dos grados y dos por profundidad, uno entre 50-75 $\mathrm{m}$ y el segundo entre 76-100 m, resultando seis celdas (Fig. 1).

En las Tablas 1 y 2 se muestra el número de individuos capturados por lance y el total por celda. 


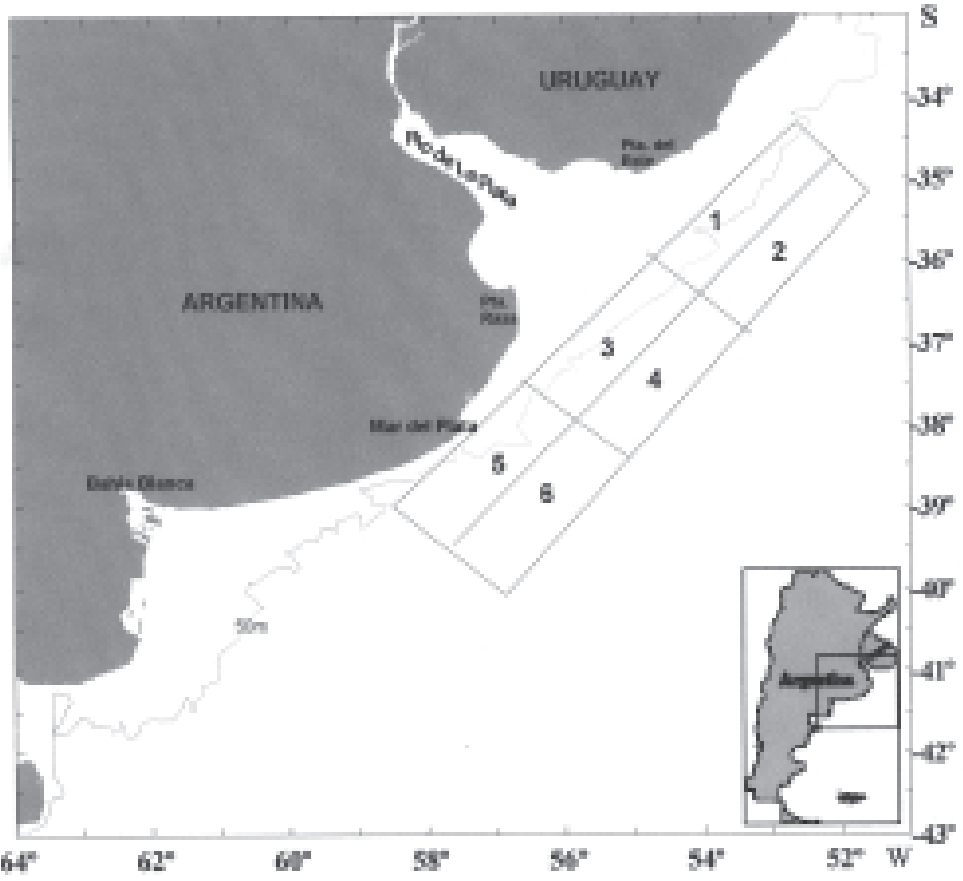

Figura 1. Mapa del área de estudio. Las divisiones corresponden a las celdas en que se dividió el área para el análisis de la información.

Figure 1. Map of the surveyed area, with the sampling design strata by latitude and depth. The numbers correspond to the strata cells in which the area was divided for data analysis.

Este diseño de $3 \times 2$ se aplicó para invierno, primavera y verano, estando directamente relacionado con la disponibilidad de datos en cada celda. En otoño no se dispuso de datos para completar la matriz de $3 \times 2$, razón por la cual se trabajaron los datos por estrato de latitud, equivalentes a los de las campañas demersales. En el caso de profundidad, también se dispuso de datos de lances de pesca realizados entre 10 y 50 m, con los cuales se creó el estrato I. Los estratos II y III correspondieron a los establecidos para las campañas demersales: 50-75 m y 76100 m. En la Figura 2a se indican los valores correspondientes a latitud solamente.

Los datos registrados por ejemplar fueron: longitud total al centímetro inferior, sexo, estadio de madurez gonadal y se extrajeron los otolitos sagita para determinar la edad. Cuando los muestreos se realizaron en tierra se registró también el peso total de cada individuo en gramos. Se muestrearon todos los individuos de cada lance de pesca. Cuando la captura del lance fue alta, como en primavera y en algunos lances en otoño, se extrajo una submuestra de 10 ejemplares por clase de longitud de un centímetro.
Tabla 1. Número de lances con captura de Xystreurys rasile y número de individuos capturado por lance, organizados por estratos de latitud y profundidad.

Table 1. Number of trawls with capture of Xystreurys rasile and number of specimens caught by trawl, ordered by latitude and depth, corresponding to autumn.

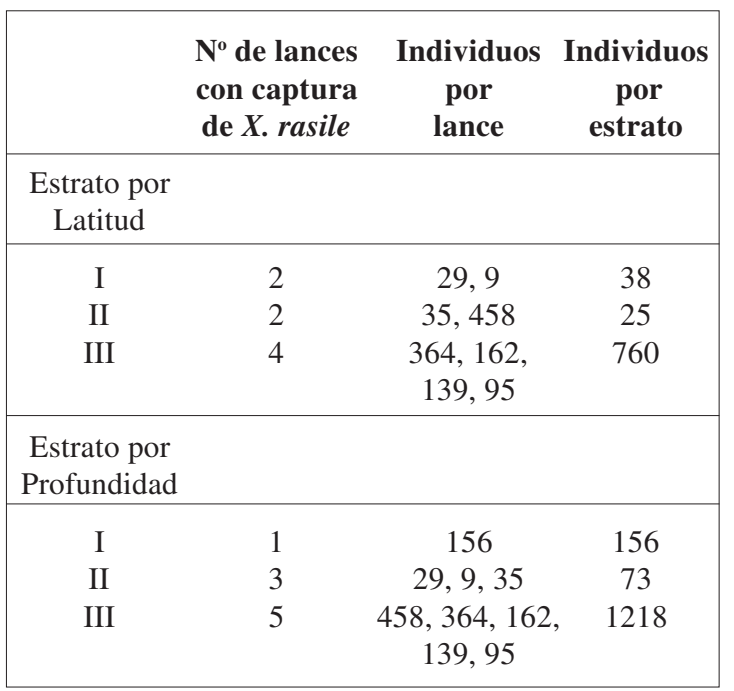


Tabla 2. Número de lances con captura de Xystreurys rasile y número de individuos capturado por lance, organizados por celda, correspondientes a las campañas demersales de invierno, primavera y verano.

Table 2. Number of trawls with capture of Xystreurys rasile and number of specimens caught by trawl, ordered by cell, corresponding to winter, spring and summer cruises.

\begin{tabular}{|c|c|c|c|}
\hline Celda & $\begin{array}{c}\mathrm{N}^{0} \text { de lances } \\
\text { con captura } \\
\text { de } X \text {. rasile }\end{array}$ & $\begin{array}{c}\text { Individuos In } \\
\text { por } \\
\text { lance }\end{array}$ & $\begin{array}{c}\text { Individuos } \\
\text { por } \\
\text { celda }\end{array}$ \\
\hline \multicolumn{4}{|c|}{ Invierno. Total de individuos: 836} \\
\hline 1 & 2 & 39,56 & 95 \\
\hline 2 & 1 & 42 & 25 \\
\hline 3 & 2 & 65,25 & 90 \\
\hline 4 & 5 & $2,105,58,36,82$ & 2322 \\
\hline 5 & 1 & 141 & 141 \\
\hline 6 & 1 & 162 & 162 \\
\hline \multicolumn{4}{|c|}{ Primavera. Total de individuos: 2047} \\
\hline 1 & 6 & $\begin{array}{c}68,19,45 \\
36,34,37\end{array}$ & 239 \\
\hline 2 & 3 & $14,53,91$ & 158 \\
\hline 3 & 1 & 92 & 92 \\
\hline 4 & 6 & $\begin{array}{l}165,91,171 \\
182,319,135\end{array}$ & 1063 \\
\hline 5 & 3 & $134,146,37$ & 317 \\
\hline 6 & 1 & 178 & 178 \\
\hline \multicolumn{4}{|c|}{ Verano. Total de individuos: 423} \\
\hline 1 & 1 & 7 & 7 \\
\hline 2 & 1 & 33 & 33 \\
\hline 3 & 2 & 78 e 30 & 108 \\
\hline 4 & 5 & $4,27,9,32,55$ & 123 \\
\hline 5 & 2 & 28,23 & 51 \\
\hline 6 & 3 & $61,11,29$ & 101 \\
\hline
\end{tabular}

Para la determinación macroscópica de los estadios de madurez gonadal se empleó la escala que describen Dell Arciprete et al. (1987) propuesta para el mero (Acanthistius brasilianus) y aplicada para especies costeras del Mar Argentino por el Laboratorio de Biología Pesquera del INIDEP. Esta escala consta de siete estadios: I: indiferenciados, II: juveniles, III: prepuesta, IV: puesta, V: postpuesta y VI: reposo gonadal. El denominado VI/III (codificado como IX en los correspondientes gráficos), representa el paso de los adultos del estado de reposo a preparación para una nueva puesta.
Para determinar la edad se consideró que la formación de los anillos hialinos en $X$. rasile ocurre en invierno (Fabré y Cousseau, 1988) y que la época de reproducción se extiende de noviembre a enero. Se establecieron dos fechas arbitrarias para la asignación de edad: la fecha de marcación, considerada como el $1^{\circ}$ de julio y la fecha de "cumpleaños" fijada al $1^{\circ}$ de enero, aplicándose la primera en este trabajo.

Las capturas en cada lance de pesca se registraron en toneladas y posteriormente se estandarizaron, llevándolas a la unidad de muestreo: densidad de pesca o captura por unidad de área (CPUA) (Sparre y Venema, 1997), en toneladas por milla náutica cuadrada (ton $/ \mathrm{mn}^{2}$ ).

\section{Análisis de los datos}

El diseño de $3 \times 2$ se aplicó de acuerdo con la disponibilidad de datos. Dentro de cada celda, o en su defecto dentro de cada estrato de latitud, se analizaron en cada estación del año: estructura de tallas; proporción sexual; proporción de estadios de madurez gonadal e índice de condición (IC), sin discriminar por sexo. El IC fue calculado como el cociente entre el peso observado ( $\mathrm{g}$ ) y el peso estimado por la relación largo-peso, calculada a partir del total de observaciones.

La estructura de tamaños y de edad, así como la proporción de estadios y de sexos se analizaron primeramente mediante estadística descriptiva y gráficos de frecuencia relativa dentro de cada estrato y celda.

El invierno, primavera y verano se trataron en conjunto mediante Análisis de Componentes Principales. La matriz estandarizada se construyó considerando como variables: los valores de talla media, talla máxima y mínima, edad media, latitud y profundidad de la celda correspondiente. Los componentes se extrajeron por la técnica varimax y los escores se representaron gráficamente para verificar la existencia de semejanzas de los vectores entre las celdas. Los cálculos se realizaron utilizando el programa STATISTICA 6.

Para el análisis de la proporción de sexos en cada celda se probó la hipótesis Ho: la proporción de sexos es independiente de la zona geográfica, versus $\mathrm{H}_{1}$ : la proporción de sexos depende de la zona geográfica. Al efecto, se construyó una tabla de contingencia de $2 \times 3$, sobre la cual se aplicó el test de $\chi^{2}$, con $\mathrm{n}-1$ grados de libertad, siendo $\mathrm{n}$ el número de celdas. 

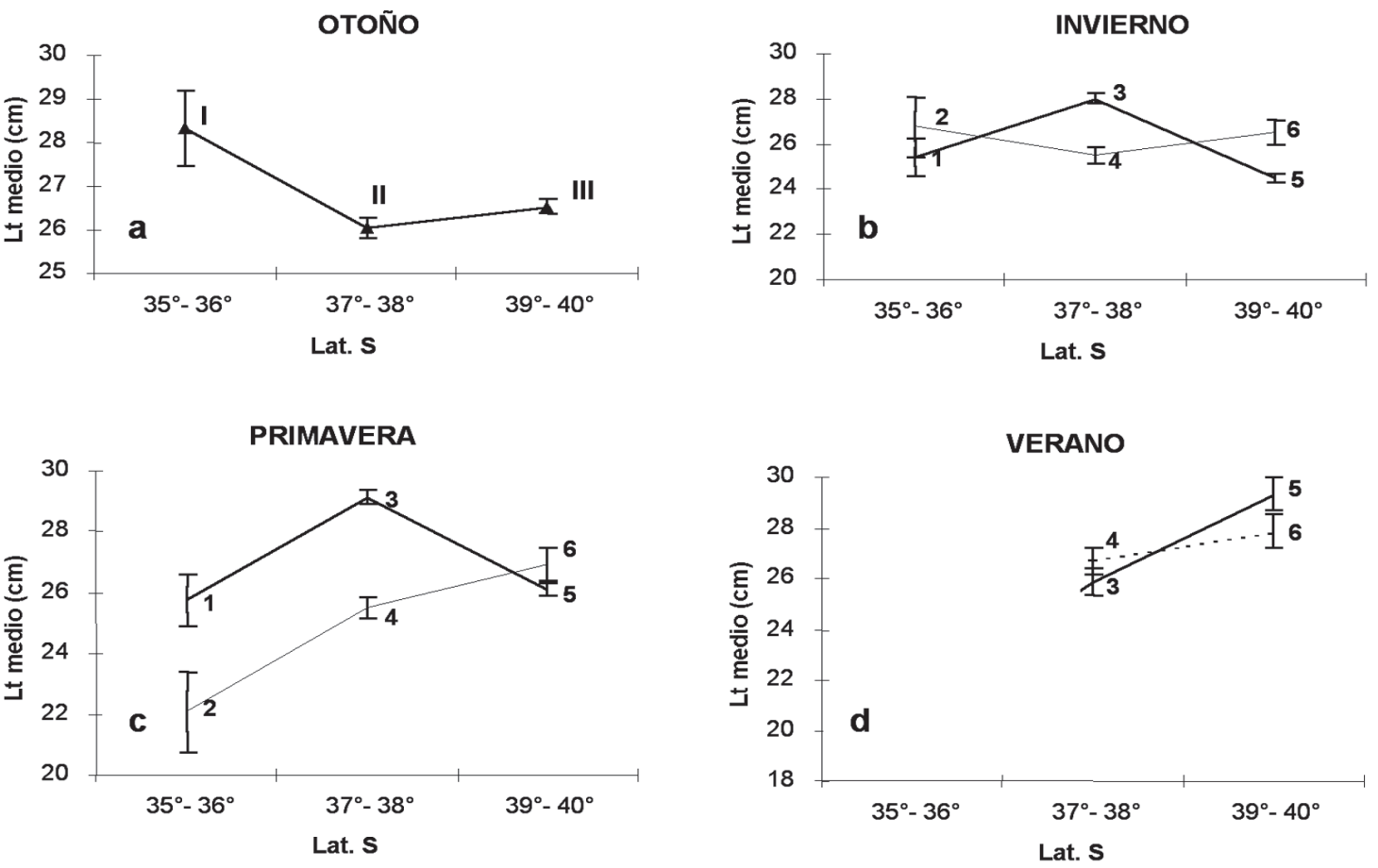

Figura 2. Valores medios de la longitud total y sus correspondientes intervalos de confianza, por estrato de latitud y de profundidad. a) otoño, b) invierno, c) primavera, d) verano.

Figure 2. Mean values of the total length and the corresponding confidence limits, for each cell. a) Autumn, b) Winter, c) Spring, d) Summer.

En los casos en que la hipótesis de independencia se rechazó, se planteó para cada celda la hipótesis extrínseca a los datos (Sokal y Rohlf, 1981), suponiendo una distribución binomial, Ho: $\mathrm{p}$ hembras $=\mathrm{q}$ machos $=0,50$. Para probar esta hipótesis se utilizó el estadístico G corregido según Sokal y Rohlf (1981).

\section{RESULTADOS}

\section{Estructura de tamaños}

En otoño los ejemplares de mayor talla se encontraron en el extremo norte del área $\left(35^{\circ}-36^{\circ} \mathrm{S}\right)$, mientras que los menores se ubicaron en latitudes intermedias $\left(37^{\circ}-38^{\circ} \mathrm{S}\right)$ (Fig. 2a). Las hembras siempre alcanzan un tamaño mayor que los machos, independientemente de la latitud y profundidad (Tabla 3).

La talla media, en otoño, aumenta al disminuir la profundidad, debido a la mayor abundancia de las hembras en aguas más costeras (Tabla 3). Ade- más, en el estrato I de profundidad, los pocos machos presentes fueron los más grandes registrados. Por el contrario, la proporción de machos en el estrato de mayor profundidad es más alta, al tiempo que la talla media de las hembras es menor.

En invierno los individuos de menor tamaño se encuentran en aguas más someras, tanto al norte $\left(35^{\circ}-36^{\circ} \mathrm{S}\right)$, como al sur $\left(39^{\circ}-40^{\circ} \mathrm{S}\right)$ (Fig. $\left.2 b\right)$. Sin embargo, se debe hacer hincapié en que entre los $37^{\circ}-38^{\circ} \mathrm{S}$ (celdas 3 y 4 , Fig. 2b), se invierte la relación entre las tallas medias observadas al norte y al sur, es decir, que en este caso, los individuos de mayor tamaño se ubican a menor profundidad. En esta época del año también las hembras superan el tamaño de los machos, pero la diferencia de longitudes entre los sexos fue menos notoria en la celda 3 (Tabla 4).

En primavera la estructura de longitudes se modifica completamente con respecto a lo observado en invierno. Entre los $35^{\circ}-38^{\circ} \mathrm{S}$ los ejemplares de mayor tamaño se ubican a menor profundidad (Fig. 2c), mientras que en latitudes mayores de $39^{\circ} \mathrm{S}$ se 
Tabla 3. Estadísticos muestrales de la longitud total (media y desviación estándar, s) por sexo y para el total de observaciones (n), por estrato de latitud y de profundidad, correspondiente al otoño. En negrita se destaca el número total por estrato.

Table 3. Statistics of the total length (mean and standard deviation, s) by sex and for the total of observations (n), corresponding to autumn. The total number of observations by stratum is detached with shady area and bold faced numbers.

\begin{tabular}{|c|c|c|c|c|c|c|}
\hline & \multicolumn{3}{|c|}{ Latitud } & \multicolumn{3}{|c|}{ Profundidad } \\
\hline & Machos & Hembras & Total & Machos & Hembras & Total \\
\hline & \multicolumn{3}{|c|}{ Estrato I } & \multicolumn{3}{|c|}{ Estrato I } \\
\hline media & 22,500 & 29,406 & 28.316 & 27,963 & 30,589 & 30,135 \\
\hline $\mathrm{s}$ & 3,507 & 3,211 & 4,101 & 3,019 & 3,141 & 3,483 \\
\hline \multirow[t]{2}{*}{$\mathrm{n}$} & 6 & 32 & 38 & 27 & 129 & 156 \\
\hline & \multicolumn{3}{|c|}{ Estrato II } & \multicolumn{3}{|c|}{ Estrato II } \\
\hline media & 25,260 & 26,822 & 26,061 & 25,000 & 29,877 & 28,808 \\
\hline $\mathrm{s}$ & 2,812 & 3,950 & 3,526 & 4,179 & 3,751 & 4,326 \\
\hline \multirow[t]{2}{*}{$\mathrm{n}$} & 238 & 253 & 493 & 16 & 57 & 73 \\
\hline & \multicolumn{3}{|c|}{ Estrato III } & \multicolumn{3}{|c|}{ Estrato III } \\
\hline media & 23,404 & 27,260 & 26,545 & 24,518 & 27,034 & 26,268 \\
\hline $\mathrm{s}$ & 1,800 & 3,723 & 3,759 & 2,582 & 3,733 & 3,013 \\
\hline $\mathrm{n}$ & 141 & 619 & 760 & 369 & 847 & 1218 \\
\hline
\end{tabular}

Tabla 4. Estadísticos muestrales (media y desviación estándar, s) por sexo, y para el total de observaciones (n) para cada celda, correspondiente al invierno. En negrita y sombreado se destaca el número de observaciones por celda.

Table 4. Statistics of total length by cell (mean and standard deviation, $s$ ) by sex and for the total of observations (n), corresponding to winter. The total number of observations in each cell is detached with shady area and bold faced numbers.

\begin{tabular}{|c|c|c|c|c|c|c|}
\hline & Machos & Hembras & Total & Machos & Hembras & Total \\
\hline & \multicolumn{3}{|c|}{ Celda 1} & \multicolumn{3}{|c|}{ Celda 2} \\
\hline media & 21,826 & 26,536 & 25,406 & & 26,792 & 26,760 \\
\hline s & 5,115 & 3,760 & 4,776 & & 3,090 & 3,032 \\
\hline \multirow[t]{2}{*}{$\mathrm{n}$} & 23 & 73 & 96 & 1 & 24 & 25 \\
\hline & \multicolumn{3}{|c|}{ Celda 3} & \multicolumn{3}{|c|}{ Celda 4} \\
\hline media & 27 & 28,423 & 28,011 & 23,381 & 27,625 & 26,523 \\
\hline $\mathrm{s}$ & 1,980 & 2,701 & 2,585 & 1,873 & 3,949 & 3,988 \\
\hline \multirow[t]{2}{*}{$\mathrm{n}$} & 26 & 64 & 90 & 42 & 120 & 162 \\
\hline & \multicolumn{3}{|c|}{ Celda 5} & \multicolumn{3}{|c|}{ Celda 6} \\
\hline media & 23,925 & 28,035 & 26,129 & 24,852 & 28,034 & 26,944 \\
\hline $\mathrm{s}$ & 2,778 & 3,791 & 4,131 & 2,315 & 3,298 & 3,352 \\
\hline $\mathrm{n}$ & 147 & 170 & 317 & 61 & 117 & 178 \\
\hline
\end{tabular}


Tabla 5. Estadísticos muestrales (media y desviación estándar, s) por sexo y para el total de observaciones (n) del longitud total, para cada celda, correspondiente a la primavera. En negrita y sombreado se destaca el número de observaciones por celda.

Table 5. Statistics of total length by cell (mean and standard deviation, $s$ ), by sex and for the total of observations (n), corresponding to winter. The total number of observations in each cell is detached with shady area and bold faced numbers.

\begin{tabular}{|c|c|c|c|c|c|c|}
\hline & Machos & Hembras & Total & Machos & Hembras & Total \\
\hline & \multicolumn{3}{|c|}{ Celda 1} & \multicolumn{3}{|c|}{ Celda 2} \\
\hline media & 22,913 & 26,663 & 25,753 & 20,806 & 22,485 & 22,095 \\
\hline s & 3,062 & 3,603 & 3,828 & 4,523 & 2,256 & 2,23 \\
\hline \multirow[t]{2}{*}{$\mathrm{n}$} & 58 & 181 & 239 & 28 & 130 & 158 \\
\hline & \multicolumn{3}{|c|}{ Celda 3} & \multicolumn{3}{|c|}{ Celda 4} \\
\hline media & 25,750 & 30,38 & 29,141 & 23,222 & 26,690 & 25,506 \\
\hline s & 4,523 & 4,511 & 4,925 & 2,567 & 3,644 & 3,708 \\
\hline \multirow[t]{2}{*}{$\mathrm{n}$} & 24 & 68 & 92 & 360 & 701 & 1063 \\
\hline & \multicolumn{3}{|c|}{ Celda 5} & \multicolumn{3}{|c|}{ Celda 6} \\
\hline media & 23,925 & 28,035 & 26,129 & 24,852 & 28,034 & 26,944 \\
\hline s & 2,778 & 3,791 & 4,131 & 2,315 & 3,298 & 3,352 \\
\hline $\mathrm{n}$ & 147 & 170 & 317 & 61 & 117 & 178 \\
\hline
\end{tabular}

Tabla 6. Estadísticos muestrales (media y desviación estándar, s) de la longitud total, por sexo, y para el total de observaciones (n); para cada celda del diseño bifactorial latitud x profundidad, correspondiente al verano. En negrita y sombreado se destaca el número de observaciones por celda.

Table 6. Statistics of total length by cell (mean and standard deviation, s) by sex and for the total of observations (n), corresponding to summer. The total number of observations in each cell is detached with shady area and bold faced numbers.

\begin{tabular}{|c|c|c|c|c|c|c|}
\hline & Machos & Hembras & Total & Machos & Hembras & Total \\
\hline & \multicolumn{3}{|c|}{ Celda 1} & \multicolumn{3}{|c|}{ Celda 2} \\
\hline media & - & 31,333 & 30,428 & - & 25,061 & 25,061 \\
\hline $\mathrm{s}$ & - & 2,699 & 2,699 & - & 2,561 & 2,561 \\
\hline \multirow[t]{2}{*}{$\mathrm{n}$} & 1 & 6 & 7 & - & 33 & 33 \\
\hline & \multicolumn{3}{|c|}{ Celda 3} & \multicolumn{3}{|c|}{ Celda 4} \\
\hline media & 24,267 & 26,769 & 26,074 & 27,333 & 27,033 & 27,041 \\
\hline $\mathrm{s}$ & 2,852 & 3,015 & 3,164 & 4,726 & 2,329 & 2,379 \\
\hline \multirow[t]{2}{*}{$\mathrm{n}$} & 30 & 78 & 108 & 3 & 120 & 123 \\
\hline & \multicolumn{3}{|c|}{ Celda 5} & \multicolumn{3}{|c|}{ Celda 6} \\
\hline media & 23,130 & 29,5 & 27,980 & 23,875 & 27,495 & 27,208 \\
\hline $\mathrm{s}$ & 2,201 & 3,144 & 3,215 & 2,532 & 3,325 & 3,404 \\
\hline $\mathrm{n}$ & 23 & 28 & 51 & 8 & 93 & 101 \\
\hline
\end{tabular}


observa lo contrario, la talla media más alta corresponde al estrato más profundo (76-100 m). Respecto a la latitud, la tendencia entre $76-100 \mathrm{~m}$, es de aumento de la talla media hacia el sur. A menor profundidad, los individuos de mayor tamaño se concentran en latitudes intermedias, entre $\operatorname{los} 37^{\circ}-38^{\circ} \mathrm{S}$ (Fig. 2c, Tabla 5).

En verano, entre los $35^{\circ}-36^{\circ} \mathrm{S}$ (celdas 1 y 2), prácticamente no hubo capturas, lo cual dificultó su caracterización (Tabla 6). Al sur de esta latitud, la media menor corresponde al estrato de menor profundidad, relación que se invierte en las celdas 5 y 6 (Fig. 2d).

\section{Distribución de edades}

En otoño el análisis de distribución de edades fue realizado solamente por latitud. El estrato I ( $35^{\circ}$ $36^{\circ} \mathrm{S}$ ) presenta características particulares (Fig. 3), como ausencia de hembras menores de cuatro años y presencia de machos pertenecientes a clases etarias menores de cuatro. De cualquier modo, el número de observaciones en este estrato es bajo. En el estrato II los machos presentan la distribución etaria más amplia, con ejemplares de dos a cinco años. Entre los $39^{\circ}-40^{\circ} \mathrm{S}$ (estrato III), están representadas mayoritariamente las clases 3 y 4 . Las hembras en todos los casos alcanzan edades mayores que los machos (Fig. 3).

Las distribuciones de edad en invierno, clasificadas por latitud y profundidad (Fig. 4) muestran que a latitudes menores la clase de edad más frecuente fue la de tres años, mientras que en las mayores la frecuencia relativa de dicha clase tiende a disminuir. En la distribución de edad de las hembras al norte $\left(35^{\circ}-36^{\circ} \mathrm{S}\right)$, y entre los 50-75 m están bien representadas las edades mayores (Fig. 4). En el caso de los machos, se destaca en la celda 4 la amplitud de la distribución de edades, ya que están representadas las clases 2 a 8 . Entre los $39^{\circ}-40^{\circ} \mathrm{S}$ no se contó con determinaciones de edad en lances con menos de $75 \mathrm{~m}$. Por lo tanto, en esta latitud sólo está representada la celda 6 , donde en ambos sexos, fueron muy abundantes los ejemplares de dos años.

En primavera la distribución etaria varía con la latitud, principalmente entre $\operatorname{los} 35^{\circ}$ y $38^{\circ} \mathrm{S}$. En las hembras se verifica una disminución de la frecuencia de la edad tres en los estratos de mayor profundidad $\left(37^{\circ}-40^{\circ} \mathrm{S}\right)$. Estas distribuciones tienen relación con los desplazamientos de la especie, como se verá más adelante. Entre los 76-100 m se observó ausencia casi total de ejemplares con más de cin-
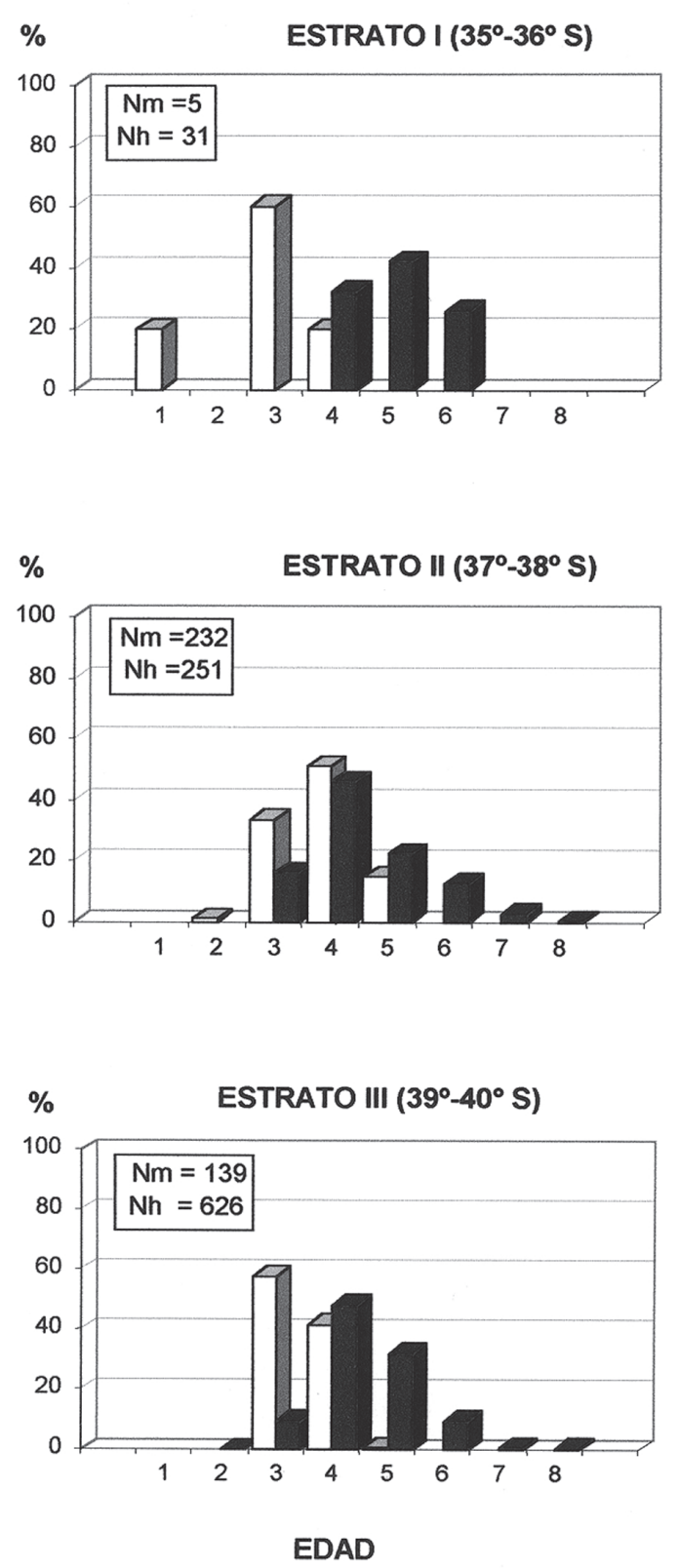

Figura 3. Frecuencia relativa de las clases etarias por estratos de latitud correspondientes al otoño. Barras blancas: machos; barras negras: hembras.

Figure 3. Relative frequency of the age classes, by latitude, corresponding to autumn. White bars: males; black bars: females.

co años y una buena representación de los mismos hacia el sur (Fig. 5). En las celdas 5 y $6\left(39^{\circ}-40^{\circ} \mathrm{S}\right)$, la frecuencia de las distintas edades es muy semejante, principalmente entre las hembras. En los ma- 
50-75 m

$\%$

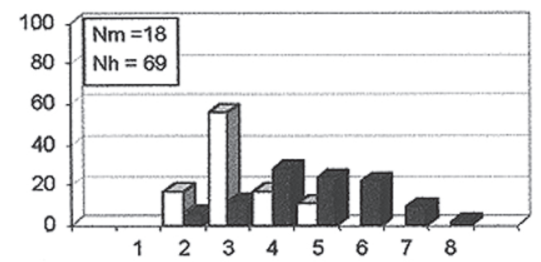

$\%$

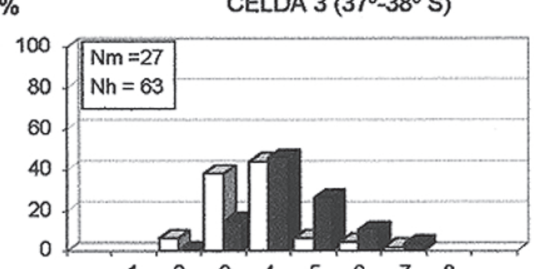

Edad
76-100 m

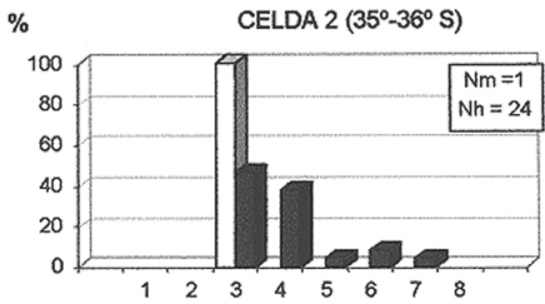

$\%$

CELDA $4\left(37^{\circ}-38^{\circ} \mathrm{S}\right)$

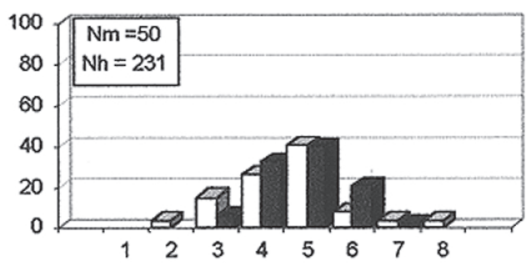

$\%$

CELDA $6\left(39^{\circ}-40^{\circ} \mathrm{S}\right)$

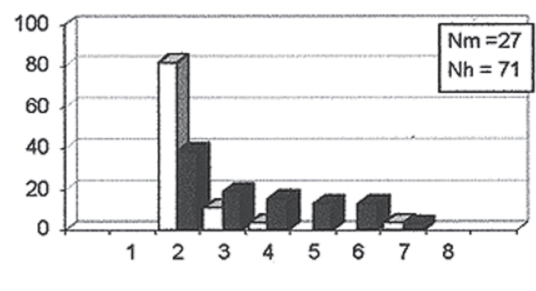

Figura 4. Frecuencia relativa de las clases etarias, por estratos de latitud y profundidad correspondientes al invierno. Barras blancas: machos; barras negras: hembras.

Figure 4. Relative frequency of the age classes, by cells, correspondent to Winter. White bars: males; black bars: females.

chos las diferencias son provocadas por las edades mayores, que son más frecuentes a mayor profundidad.

En verano las diferencias entre celdas sólo pudieron ser consideradas a partir de $\operatorname{los} 36^{\circ} \mathrm{S}$, porque al norte de esta latitud el número de ejemplares capturados fue muy bajo. Esta estación se caracteriza por la ausencia en toda el área de ejemplares jóvenes: la clase etaria dos está completamente ausente y la tres presenta frecuencias relativas muy bajas. Las frecuencias relativas de las mayores clases etarias son muy semejantes a las obtenidas en pri- mavera. Puede deducirse que la frecuencia relativa de las edades 5, 6 y 7, aparentemente mayor, se debe a la emigración de las clases anuales 2, 3 y 4, más que a una inmigración de ejemplares más viejos.

El Análisis de Componentes Principales (ACP) permitió realizar un estudio conjunto de las variaciones en longitud, edad en las diferentes estaciones del año, latitud y profundidad. Los resultados indican que el primer componente (longitud total y edad) explica el $35,7 \%$ de la variabilidad total y el segundo componente (longitud total máxima, latitud y profundidad) el $24,8 \%$ y por lo tanto el por- 
50-75 m 76-100 m

$\%$

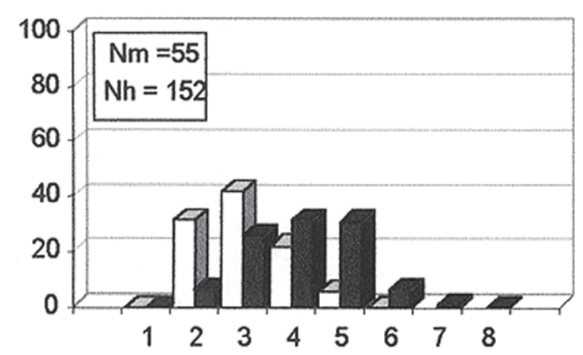

$\%$

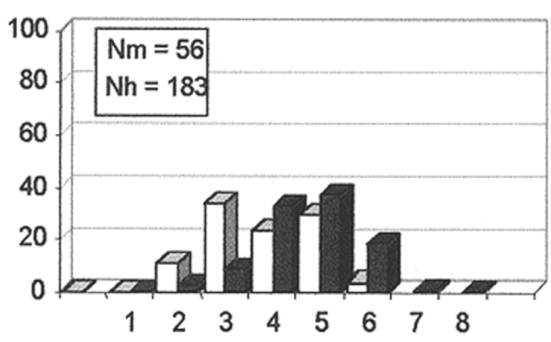

$\%$

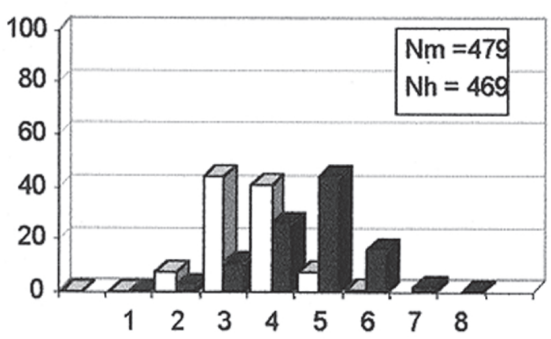

EDAD
CELDA $2\left(35^{\circ}-36^{\circ} \mathrm{S}\right)$

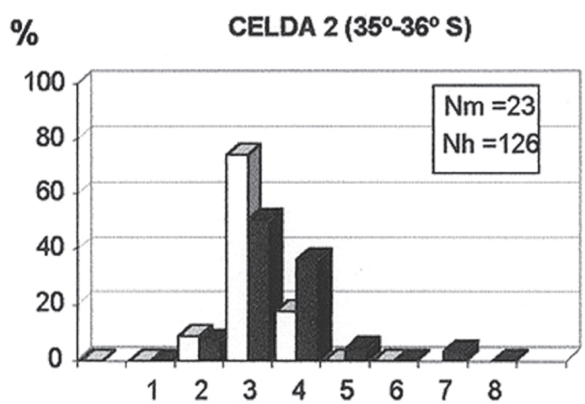

$\% \quad$ CELDA $4\left(37^{\circ}-38^{\circ} \mathrm{S}\right)$

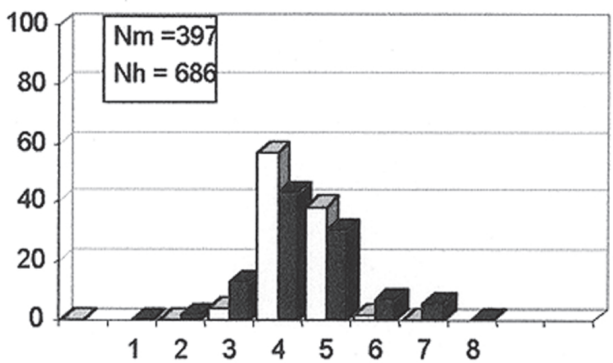

$\%$

CELDA $6\left(39^{\circ}-40^{\circ} \mathrm{S}\right)$

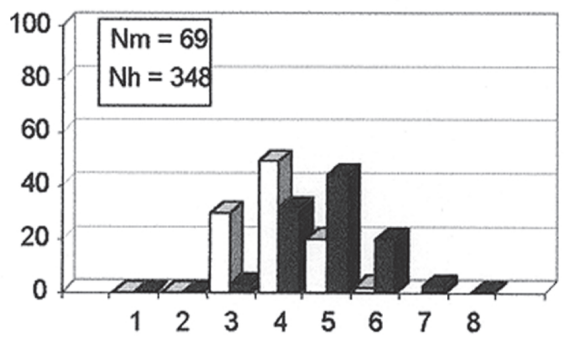

EDAD

Figura 5. Frecuencia relativa de las clases etarias, por estratos de latitud y profundidad correspondientes a primavera. Barras blancas: machos; barras negras: hembras.

Figure 5. Relative frequency of the age classes, by cells, correspondent to Spring. White bars: males; black bars: females. 
Factor 1 - LT, - Edad Factor $2 \sim$ + Prof. , - Lat.

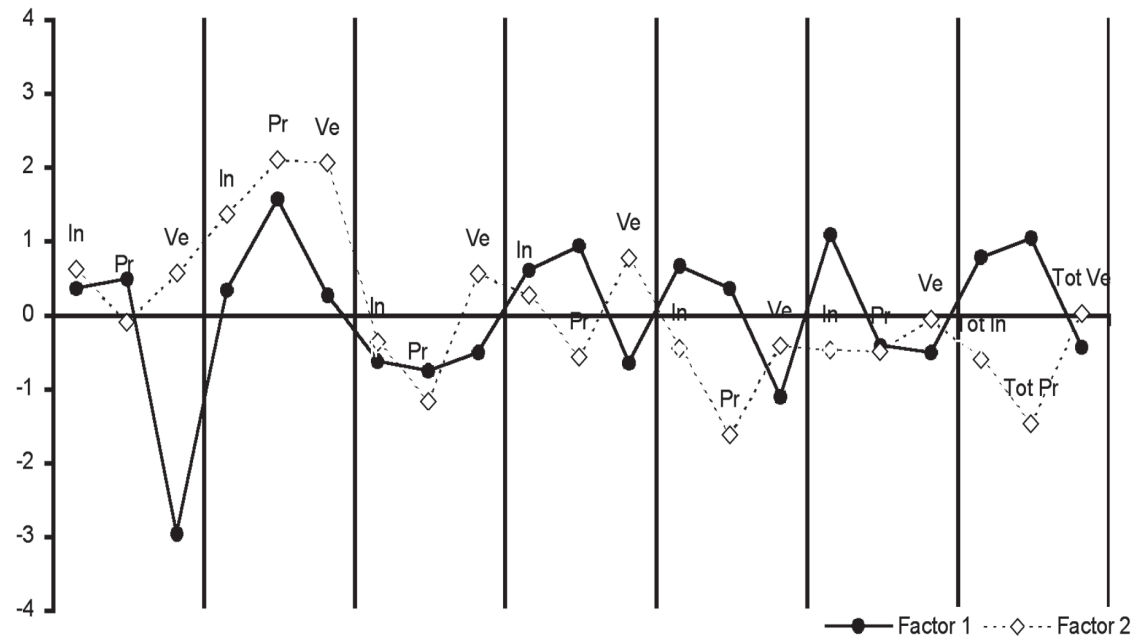

Figura 6. Escores de los factores 1 y 2 resultantes de la extracción de los componentes principales.

Figure 6. Scores of the factors 1 and 2 of principal components.

centaje acumulado de explicación de la varianza es de $60,5 \%$. Los factores de ponderación de cada variable asociados a los dos primeros componentes se presentan en el siguiente cuadro:

\begin{tabular}{lcccccc}
\hline & LT & Edad & \multicolumn{2}{c}{ Prof. Latitud } & $\begin{array}{c}\text { LT } \\
\text { máx. }\end{array}$ & $\begin{array}{c}\text { Lt } \\
\text { mín. }\end{array}$ \\
\hline Factor 1 & $-0,86$ & $-0,89$ & 0,38 & 0,10 & 0,21 & $-0,69$ \\
Factor 2 & $-0,32$ & $-0,14$ & 0,58 & $-0,55$ & $-0,88$ & 0,41 \\
\hline
\end{tabular}

La representación gráfica de los escores de cada factor (Fig. 6), permite hacer la siguiente generalización: hay una tendencia al predominio de las tallas menores en aguas más costeras, principalmente entre $\operatorname{los} 35^{\circ}-38^{\circ} \mathrm{S}$, y un aumento en la longitud media hacia el sur. Este patrón sufre algunas modificaciones estacionales, observándose una tendencia al aumento de la longitud media entre invierno y verano. En general, cuando se analiza el efecto conjunto de latitud y profundidad, prevaleció un efecto conjunto sobre cualquiera de aquellos considerados en forma aislada.

\section{Reproducción}

En otoño la mayoría de las hembras se encontraba en reposo gonadal (estadio VI), en tanto que los machos estaban principalmente en postpuesta. También hubo hembras en postpuesta (estadio V), pero en un porcentaje bajo. La proporción de los distintos estadios de madurez gonadal varió latitudinalmente. Dicha variación estuvo relacionada principalmente con la presencia o ausencia de juveniles (estadio II) y de individuos en prepuesta (estadio III). Los juveniles fueron más abundantes en los estratos I y II, mientras que lo contrario se observó con los ejemplares en prepuesta, más abundantes en el extremo sur del área estudiada (Fig. 7).

Fue notable el elevado porcentaje de machos en estadio II en toda el área de estudio. Esto se puede deber a que en los machos es difícil distinguir macroscópicamente el estadio II del VI. Por esta razón, el porcentaje de machos juveniles estaría sobreestimado. La hipótesis de independencia de la proporción de sexos de la región geográfica fue rechazada con un error menor del $1 \%\left(\chi_{\text {obs }}^{2}=131,18\right)$. Se determinó que en el estrato II de latitud, comprendido entre los $37^{\circ}-38^{\circ} \mathrm{S}$, la proporción sexual es de $1: 1\left(\mathrm{G}_{\mathrm{obs}}=0,458<\chi_{(0.05,1)}^{2}=3,84\right)$.

En invierno se consideraron las frecuencias relativas de cada estadio de madurez por estratos de latitud y profundidad (Fig. 8). Tanto machos como hembras se encontraron en reposo gonadal. Sin embargo, en esta época se comienzan a observar indicios de actividad sexual, por la presencia de machos en preparación para la puesta (estadio VI/ III = IX) y hembras en prepuesta (III). Hacia el sur fueron más frecuentes los individuos saliendo del 
$\% \quad$ ESTRATO I $\left(35^{\circ}-36^{\circ} \mathrm{S}\right)$

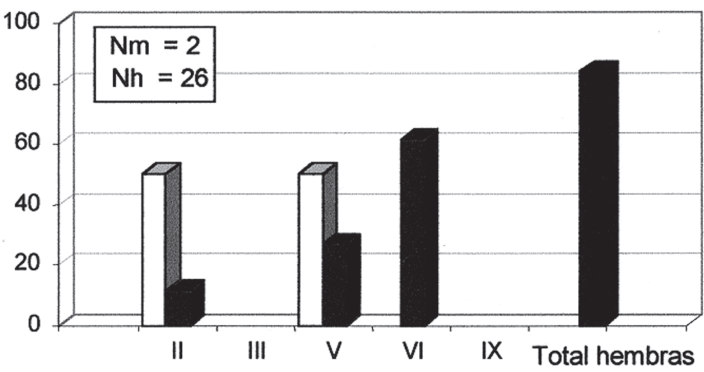

$\% \quad$ ESTRATO II $\left(37^{\circ}-38^{\circ} \mathrm{S}\right)$

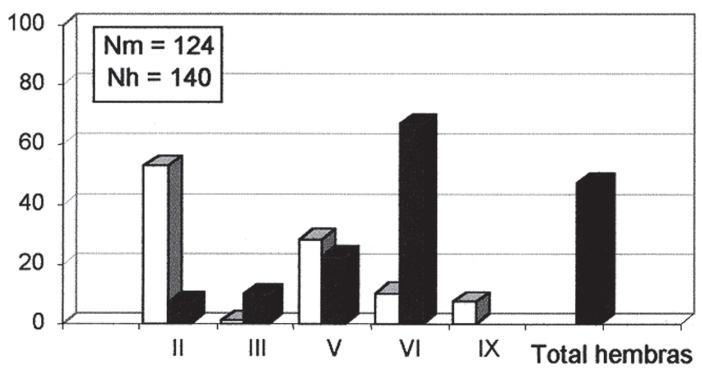

$\% \quad$ ESTRATO III $\left(39^{\circ}-40^{\circ} \mathrm{S}\right)$

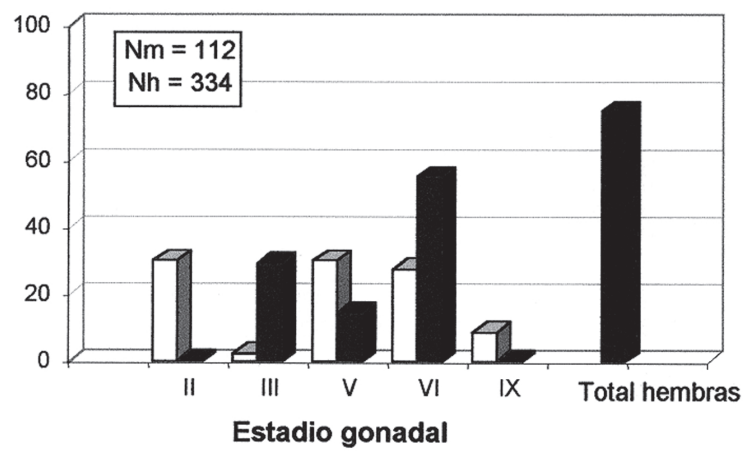

Figura 7. Frecuencia relativa de los estadios de madurez gonadal, por estratos de latitud correspondientes al otono. Barras blancas: machos; barras negras: hembras. La barra de la derecha indica el porcentaje total de hembras en cada celda.

Figure 7. Relative frequency of the gonad maturity stages, by latitude, corresponding to Autumn. White bars: males; black bars: females. The right black bar indicates the total number of females in each stratum. reposo gonadal para entrar en maduración (estadio VI/III = IX, Fig. 4). En todas las celdas el porcentaje de hembras supera el 50\% (Fig. 8), siendo rechazada la hipótesis de independencia de la proporción sexual del área geográfica, así como la hipótesis intrínseca de proporción sexual 1:1, con un error menor del $1 \%$.

En primavera ambos sexos se encuentran en plena actividad reproductiva, indicada por los elevados porcentajes de ejemplares en prepuesta en toda el área (Fig. 9). Entre los $35^{\circ}-36^{\circ} \mathrm{S}$ (celdas 1 y 2), el porcentaje de este estadio fue más bajo que en las restantes celdas. Otra característica particular de las celdas 1 y 2 es la mayor frecuencia de juveniles, tanto machos como hembras, especialmente notoria en la celda 1 . Existe una tendencia de disminución del porcentaje de ejemplares en estadio VI y un aumento del estadio III hacia el sur y a menor profundidad. El estadio VI alcanza su frecuencia mínima en la celda 5, coincidiendo con la frecuencia máxima del III (Fig. 9). En todas las celdas, con excepción de la 5, las hembras representan casi el $80 \%$ del total de observaciones. Esta variación en la proporción de sexos con la región geográfica resultó estadísticamente significativa $(\mathrm{p}<0,05)$. Se comprobó que en la celda 5 la proporción sexual es de $1: 1\left(\mathrm{G}_{\mathrm{obs}}=\right.$ $\left.0,635<\chi^{2} \operatorname{crit}_{(1 ; 0,25)}=1,3\right)$, mientras que en las cinco celdas restantes, la hipótesis nula de igual proporción sexual fue rechazada.

En verano las hembras se encontraban principalmente en reposo gonadal, siguiendo en orden de frecuencia el estadio $\mathrm{V}$ o de postpuesta (Fig. 10). Lo contrario sucedió con los machos, que se encontraban en su mayoría en postpuesta y prepuesta. A esta estación le corresponde la frecuencia más baja de ejemplares en estadio II (Fig. 10), indicando escasa presencia de juveniles en el área. En esta estación las diferencias entre celdas no son muy evidentes. Las escasas variaciones observadas parecen estar más relacionadas con la profundidad, registrándose mayores frecuencias de ejemplares en pospuesta entre los 76 y 100 m (celdas 4 y 6). Es notable que prácticamente no existan individuos en estadio $\mathrm{V}$ al norte del área (celdas 1 y 2), mientras que abundan ejemplares en estadio VI de reposo gonadal.

Estas observaciones se refieren principalmente a las hembras, ya que los machos están 
50-75 m

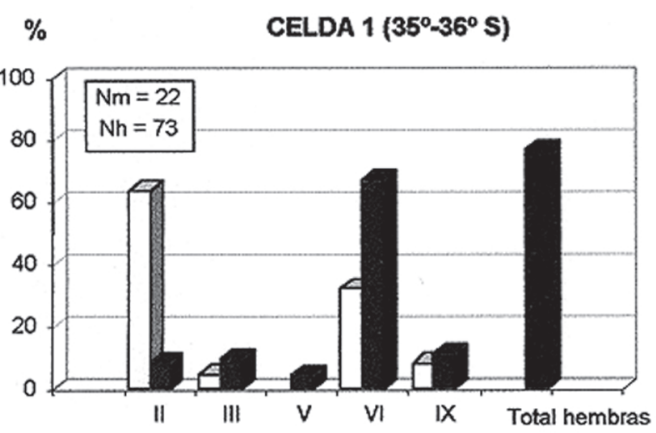

$\% \quad$ CELDA $3\left(37^{\circ}-38^{\circ} \mathrm{S}\right)$

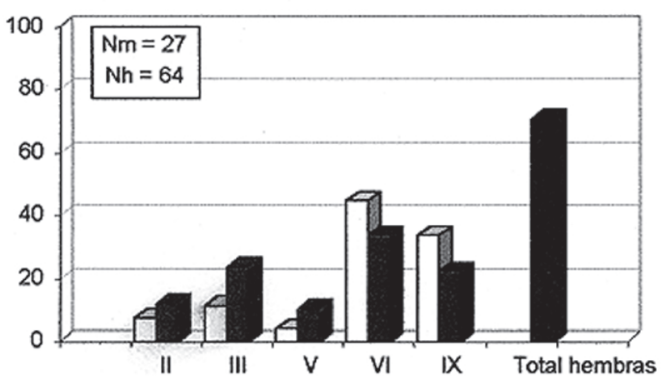

$\%$

CELDA $5\left(39^{\circ}-40^{\circ} \mathrm{S}\right)$

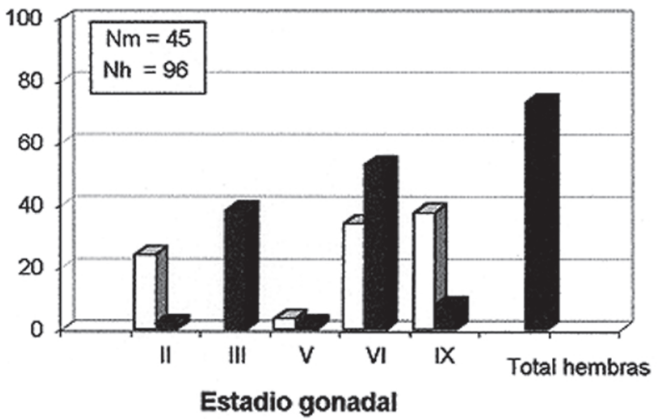

76-100 m
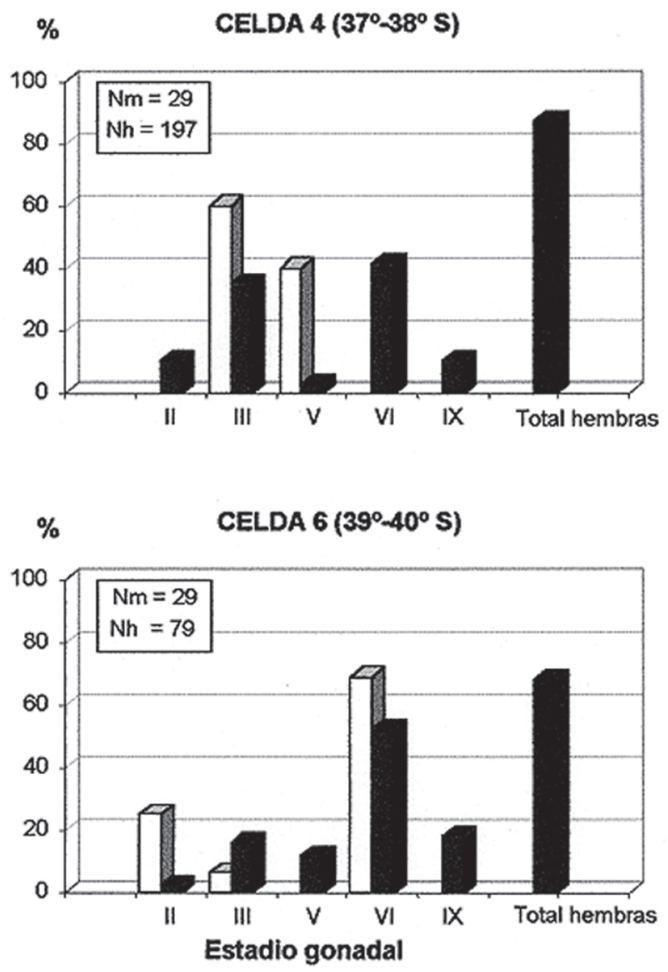

Figura 8. Variación de la frecuencia relativa de los estadios de madurez gonadal, por estratos de latitud y profundidad, correspondiente al invierno. Barras blancas: machos; barras negras: hembras. La barra de la derecha indica el porcentaje total de hembras en cada celda.

Figure 8. Relative frequency of the gonad maturity stages, by latitude, corresponding to Winter. White bars: males; black bars: females. The right black bar indicates the total number of females in each stratum.

prácticamente ausentes entre los $35^{\circ}-36^{\circ} \mathrm{S}$, así como entre los 76-100 $\mathrm{m}$ de profundidad (celdas 4 y 6). En verano no se pudo probar la hipótesis de independencia de la proporción sexual respecto a la región geográfica, debido el bajo número de observaciones, solamente en la celda 5 se aceptó la hipóte- sis de igualdad de proporción sexual.

\section{Indice de Condición (IC)}

Se analizó el índice de condición (IC) sin discriminar sexo en otoño, primavera y verano, estaciones para las cuales se dispuso de datos de peso por ejemplar. 


\section{0-75 m}

$\%$

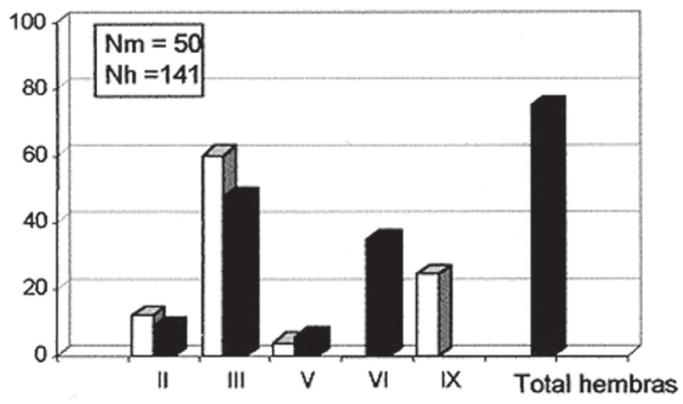

$\%$

CELDA $3\left(37^{\circ}-38^{\circ} \mathrm{S}\right)$

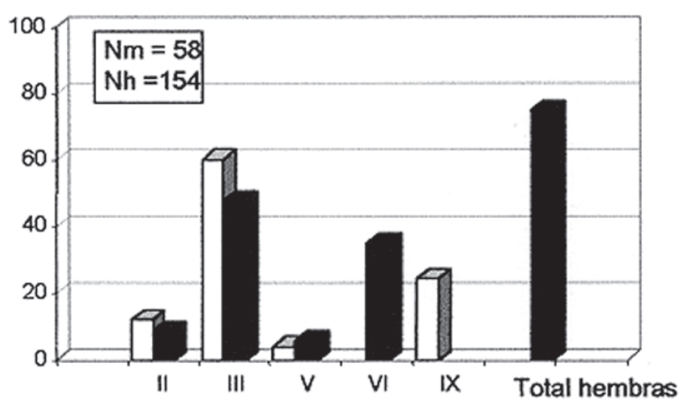

$\%$

CELDA $5\left(39^{\circ}-40^{\circ} \mathrm{S}\right)$

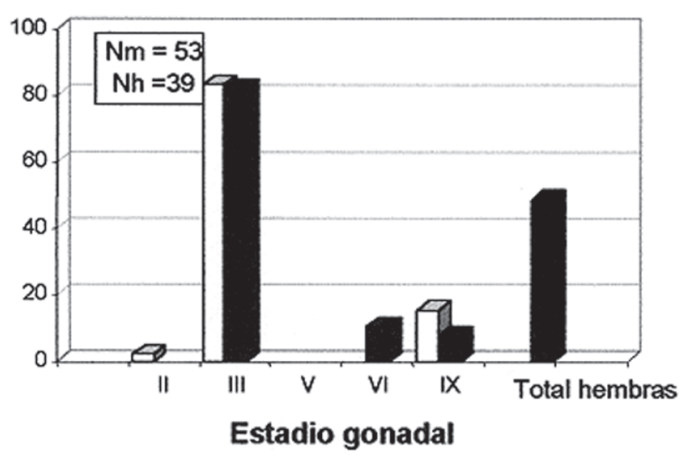

76-100 m

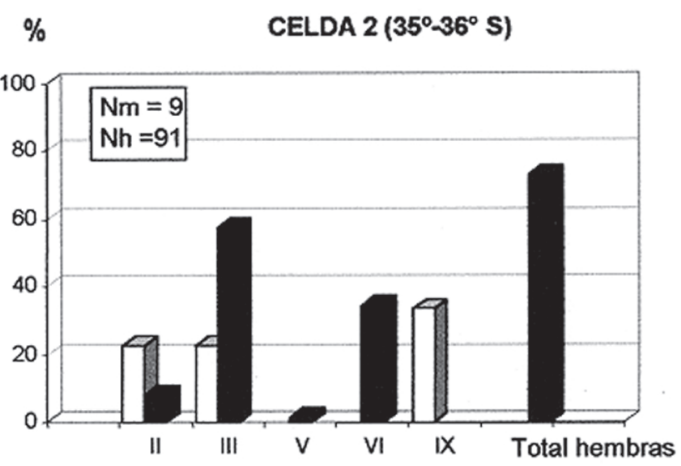

$\% \quad$ CELDA $4\left(37^{\circ}-38^{\circ} \mathrm{S}\right)$

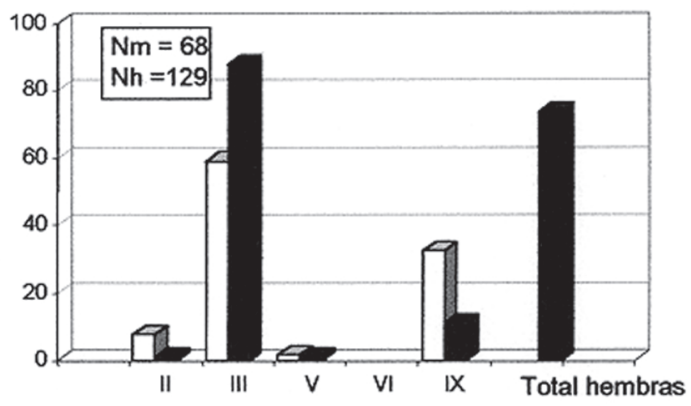

$\% \quad$ CELDA $6\left(39^{\circ}-40^{\circ} \mathrm{S}\right)$

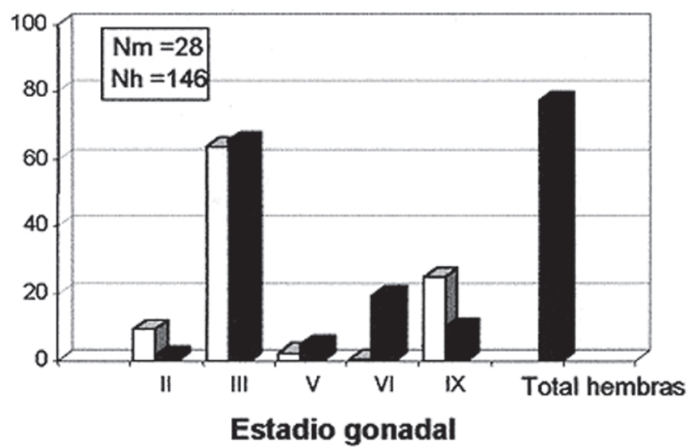

Figura 9. Variación de la frecuencia relativa de los estadios de madurez gonadal, por estratos de latitud y profundidad, correspondiente a la primavera. Barras blancas: machos; barras negras: hembras. La barra de la derecha indica el porcentaje total de hembras en cada celda.

Figure 9. Relative frequency of the gonad maturity stages, according to the cells, corresponding to Spring. White bars: males; black bars: females. The right black bar indicates the total number of females in each cell. 
50-75 m
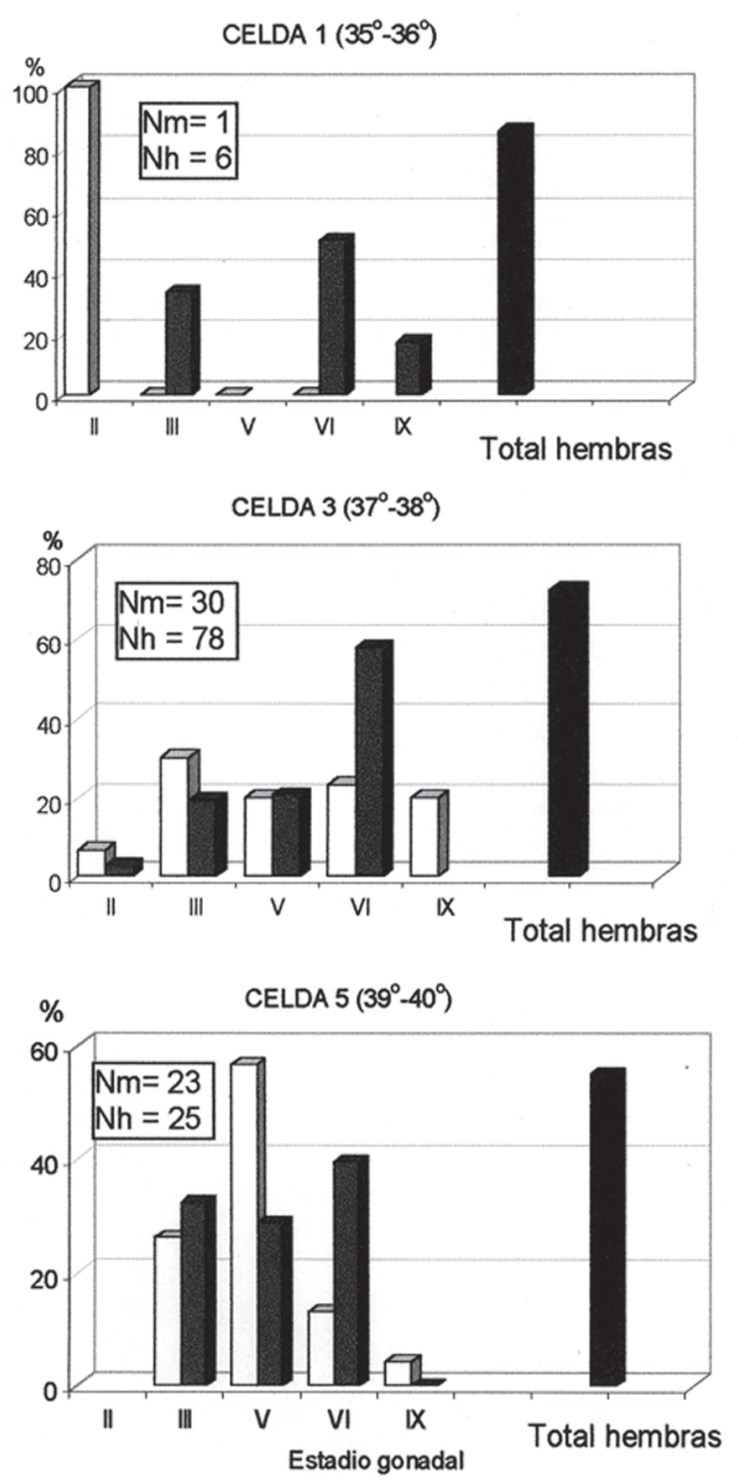

76-100 m
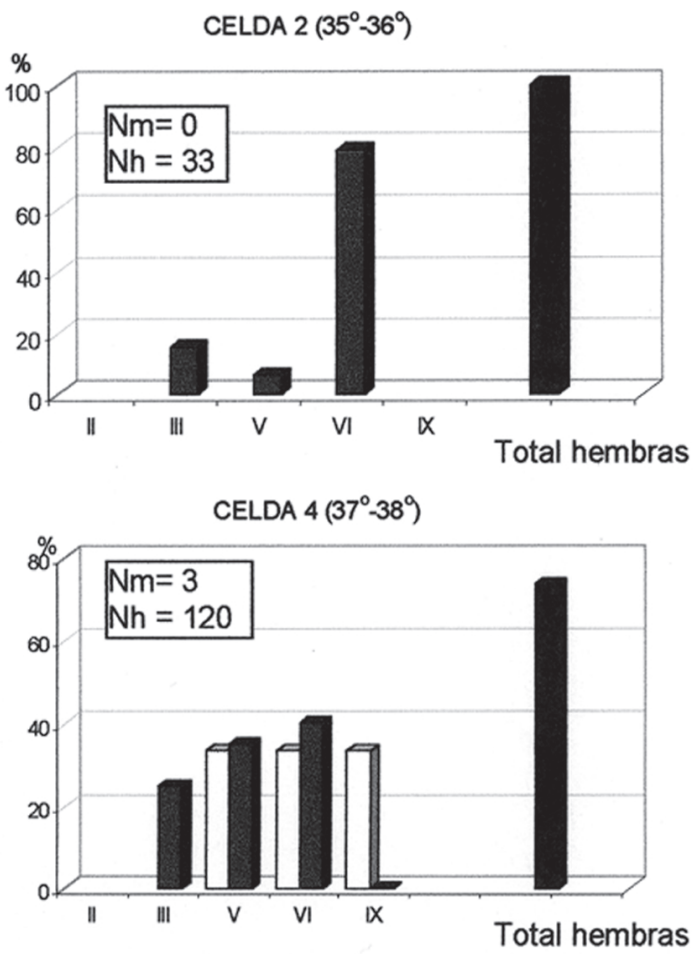

CELDA $6\left(39^{\circ}-40^{\circ}\right)$

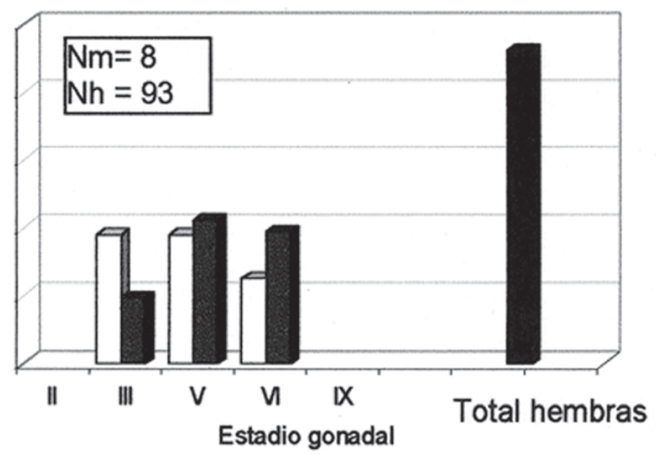

Figura 10. Variación de la frecuencia relativa de los estadios de madurez gonadal, por estratos de latitud y profundidad, correspondiente al verano. Barras blancas: machos; barras negras: hembras. La barra de la derecha indica el porcentaje total de hembras en la celda.

Figure 10. Relative frequency of the gonad maturity stages, according to the cells, corresponding to Summer. White bars: males; black bars: females. The right black bar indicates the total number of females in each cell. 
En otoño se calcularon los índices promedio para cada estrato de latitud y de profundidad separadamente. En el primer caso, las varianzas resultaron heterogéneas $\left(\mathrm{F}_{\mathrm{obs}}=18,08>\mathrm{Fcrit}_{(2 ; 732 ; 0,99)}\right)$. Se observó un incremento del índice de condición con la latitud, alcanzando su valor máximo entre los 39 y $40^{\circ} \mathrm{S}$, siendo la media en este estrato significativamente diferente de las correspondientes a los estratos I y II $(\propto=0,05)$ (Tabla 7$)$. Al considerar el IC por profundidad, las varianzas fueron homogéneas $\left(\mathrm{F}_{\mathrm{obs}}=0,71<\operatorname{Fcrit}_{(1 ; 733 ; 0,95)}\right)$.

En primavera los cálculos del IC fueron realizados por latitud y profundidad (Tabla 7). Las varianzas de las diferentes celdas, considerando tanto el factor principal latitud $\left(\mathrm{F}_{\mathrm{obs}}=31,38>\operatorname{Fcrit}_{(2 ; 1681 ; 0,99)}\right)$ como el interactivo, fueron estadísticamente diferentes $\left(F_{\text {obs }}=14,24>F_{c r i t}(2 ; 1681 ; 0,99)\right)$. Cuando se toman los valores de IC respecto a la profundidad, las varianzas son heterogéneas $(\mathrm{p}<0,05)$. Los valores medios del índice de condición de las celdas 4 y 6 fueron significativamente mayores que los correspondientes a las celdas $1,2,3$ y 5 , siendo la media de la celda 3 la menor dentro del área en esta época (Tabla 7).

En verano, al igual que en otoño, los IC fueron estimados por estratos de profundidad y latitud por separado, debido al bajo número de peces capturados en este período del año. Las varianzas asocia- das a cada media resultaron homogéneas $\left(\mathrm{F}_{\mathrm{obs}}=0,36\right.$ $<$ Fcrit $\left._{(2 ; 420 ; 0,95)}\right)$ cuando se consideró la latitud como factor y heterogéneas en el caso de la profundidad $\left(\mathrm{F}_{\text {obs }}=9,13>\mathrm{Fcrit}_{(1,421 ; 0,99)}\right)$, habiendo tendencia a medias más elevadas a mayor profundidad (Tabla 7).

\section{Estimación de talla y edad de primera madurez}

Este parámetro poblacional se estimó a partir de los datos de la campaña de primavera de 1986, época en que los individuos están en plena actividad reproductiva, preparándose para la puesta, de esa manera se trató de evitar la confusión entre estadios II y V. Además, en primavera se observó el mayor rango de tallas $(13-44 \mathrm{~cm})$. Se ajustó una curva logística a los porcentajes de individuos en estadios III, IV y $\mathrm{V}$ por clase de longitud de $1 \mathrm{~cm}$ y por edad. Los resultados de este ajuste, para ambos sexos, indicados por el punto de inflexión de la logística fueron para machos $=20,0 \mathrm{~cm}$ y hembras $=21,2 \mathrm{~cm}$ (Fig. 11). En relación a la edad de primera madurez sexual, los resultados fueron para machos $=1,29$ años y hembras $=1,94$ años.

\section{Variación espacio-temporal de la densidad}

En otoño la especie presentó densidades de pesca muy bajas $\left(<0,5 \mathrm{ton} / \mathrm{mn}^{2}\right)$ al norte de $\operatorname{los} 37^{\circ} \mathrm{S}$, principalmente entre $\operatorname{los} 34^{\circ}-35^{\circ} \mathrm{S}$ y a profundidades

Tabla 7. Valores medios del índice de condición y número de observaciones (n), por estrato de latitud y profundidad para el otoño y el verano, y por celda para la primavera.

Table 7. Mean values of the condition index and number of observations (n), by latitude and by depth for autumn and summer and by cell for spring.

\begin{tabular}{|c|c|c|c|c|c|c|}
\hline \multirow{2}{*}{$\begin{array}{c}\text { Otoño } \\
\text { Estrato }\end{array}$} & \multicolumn{3}{|c|}{ Latitud } & & \multicolumn{2}{|c|}{ Profundidad } \\
\hline & I & II & III & & I & II \\
\hline $\mathrm{n}$ & 27 & 263 & 445 & & 69 & 665 \\
\hline media & 0,954 & 0,972 & 1,003 & & 0,993 & 1,006 \\
\hline Primavera & \multicolumn{6}{|c|}{ Latitud x Profundidad } \\
\hline Celda & 3 & 2 & 5 & 1 & 4 & 6 \\
\hline $\mathrm{n}$ & 201 & 140 & 377 & 202 & 551 & 216 \\
\hline media & 0,670 & 0,815 & 0,825 & 0,840 & 0,937 & 0,941 \\
\hline Verano & \multicolumn{3}{|c|}{ Latitud } & & \multicolumn{2}{|c|}{ Profundidad } \\
\hline Estrato & I & II & III & & I & II \\
\hline $\mathrm{n}$ & 40 & 231 & 152 & & 166 & 257 \\
\hline media & 1,089 & 0,860 & 0,864 & & 0,994 & 1,197 \\
\hline
\end{tabular}



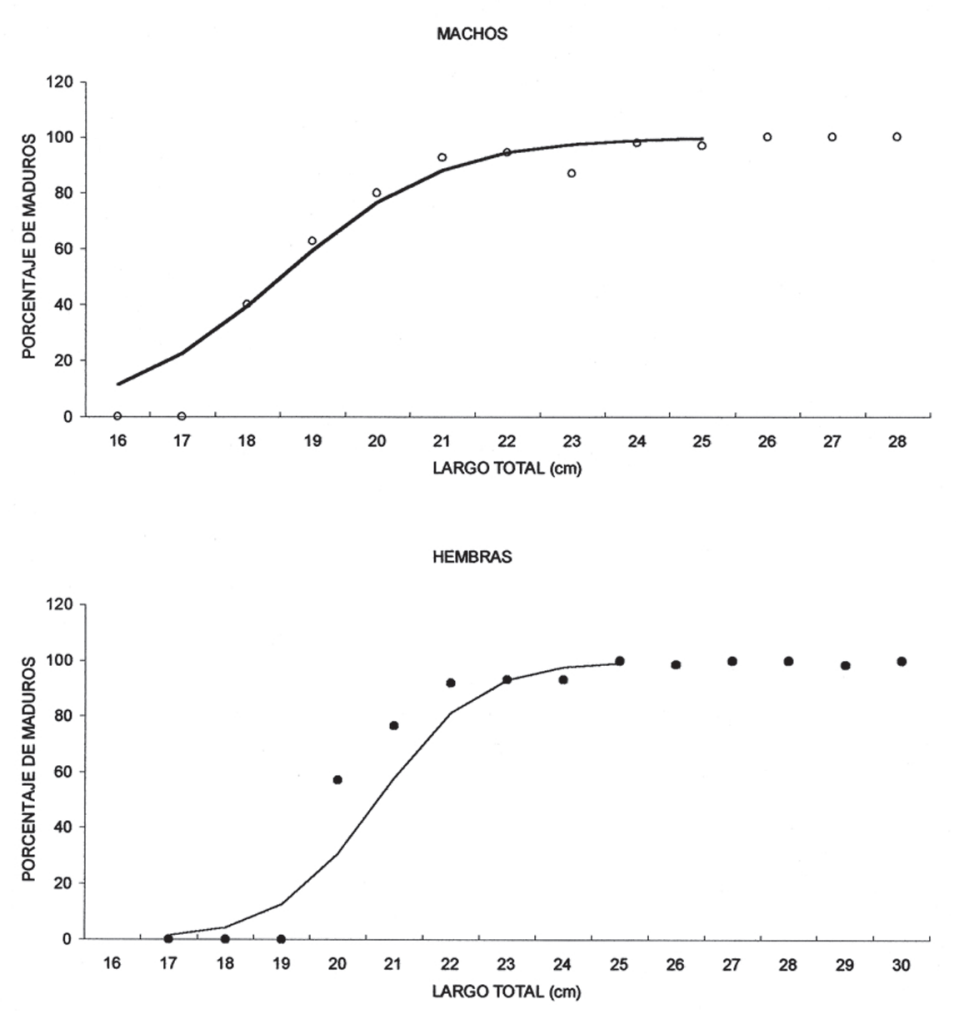

Figura 11. Curva logística ajustada a los valores de porcentaje de individuos maduros en relación a la longitud del cuerpo, separado por sexos.

Figure 11. Logistic curve for each sex, corresponding to the percentage of mature specimens in relation to the total length.

inferiores a $65 \mathrm{~m}$ (Fig. 12). Cabe destacar que a los $37^{\circ} \mathrm{S}$ se registraron capturas entre $85-95 \mathrm{~m}$. A partir de $\operatorname{los} 38^{\circ} \mathrm{S}$, la abundancia manifiesta un notorio incremento, el cual se acentúa entre los $39^{\circ}-40^{\circ} \mathrm{S}$. Este aumento de la abundancia está relacionado con un rango de profundidad comprendido entre los 65-95 m. Superada esta última profundidad se verifica ausencia de esta especie.

En invierno este lenguado se encuentra distribuido más homogéneamente que en otoño (Fig. 12). Las altas densidades observadas al sur de los $38^{\circ} \mathrm{S}$ en el otoño han disminuido notoriamente en invierno en tanto que han aumentado al norte de los $38^{\circ} \mathrm{S}$, pero sólo entre los 75-95 m. Cabe señalar que durante esta estación se observó la profundidad máxima con captura de la especie a $129 \mathrm{~m}$.

En primavera, $X$. rasile alcanza su abundancia máxima y se observa una relación muy evidente con la latitud (Fig. 12). Al igual que en otoño, se observa un aumento de la densidad hacia el sur. Este incremento no es paulatino, sino que a partir de los $39^{\circ} \mathrm{S}$ provoca un máximo de abundancia muy pronunciado, alcanzando una densidad media mayor a 6 ton/mn². Este máximo, al igual que en otoño, se asocia a la profundidad, que en este caso corresponde a los 65-75 m. En esta esta-

ción también se observan valores relativamente altos en sectores más próximos a la costa. Este comportamiento es más evidente al norte de $\operatorname{los} 37^{\circ} \mathrm{S}$, pero igualmente al sur de esta latitud se verifica un máximo de abundancia entre los 55-65 m.

El verano se caracteriza por la brusca caída de la abundancia en toda el área, siendo difícil identificar algún patrón. En todos los estratos muestreados la abundancia es muy baja, aunque se evidencia una tendencia a densidades relativamente más altas en profundidades mayores, registrándose capturas a más de $95 \mathrm{~m}$, entre los estratos de $36^{\circ}-37^{\circ} \mathrm{S}$, en los cuales la densidad fue cero en primavera (Fig. 12).

\section{DISCUSIÓN}

\section{Variación espacio-temporal de la estructura poblacional}

Se verificó una alta variabilidad en las distribuciones de tallas, en la proporción de sexos, en los estadios de madurez y en las distribuciones etarias, por varias causas. En las zonas de mayor profundidad la estructura de tallas se mantuvo más estable, mientras que entre los 50-75 m de profundidad ocurrieron marcados cambios estacionales. La causa de estas variaciones estacionales se relacionó estrechamente con la latitud. En otoño y verano, entre los $35^{\circ}-36^{\circ} \mathrm{S}$, la talla media fue mayor que entre los $37^{\circ}-38^{\circ} \mathrm{S}$, siendo que en primavera, en este sector geográfico se capturaron los mayores ejemplares. En el extremo sur del área analizada, las tallas medias mayores se observaron en primavera y verano. McCracken (1963), al describir los movi- 

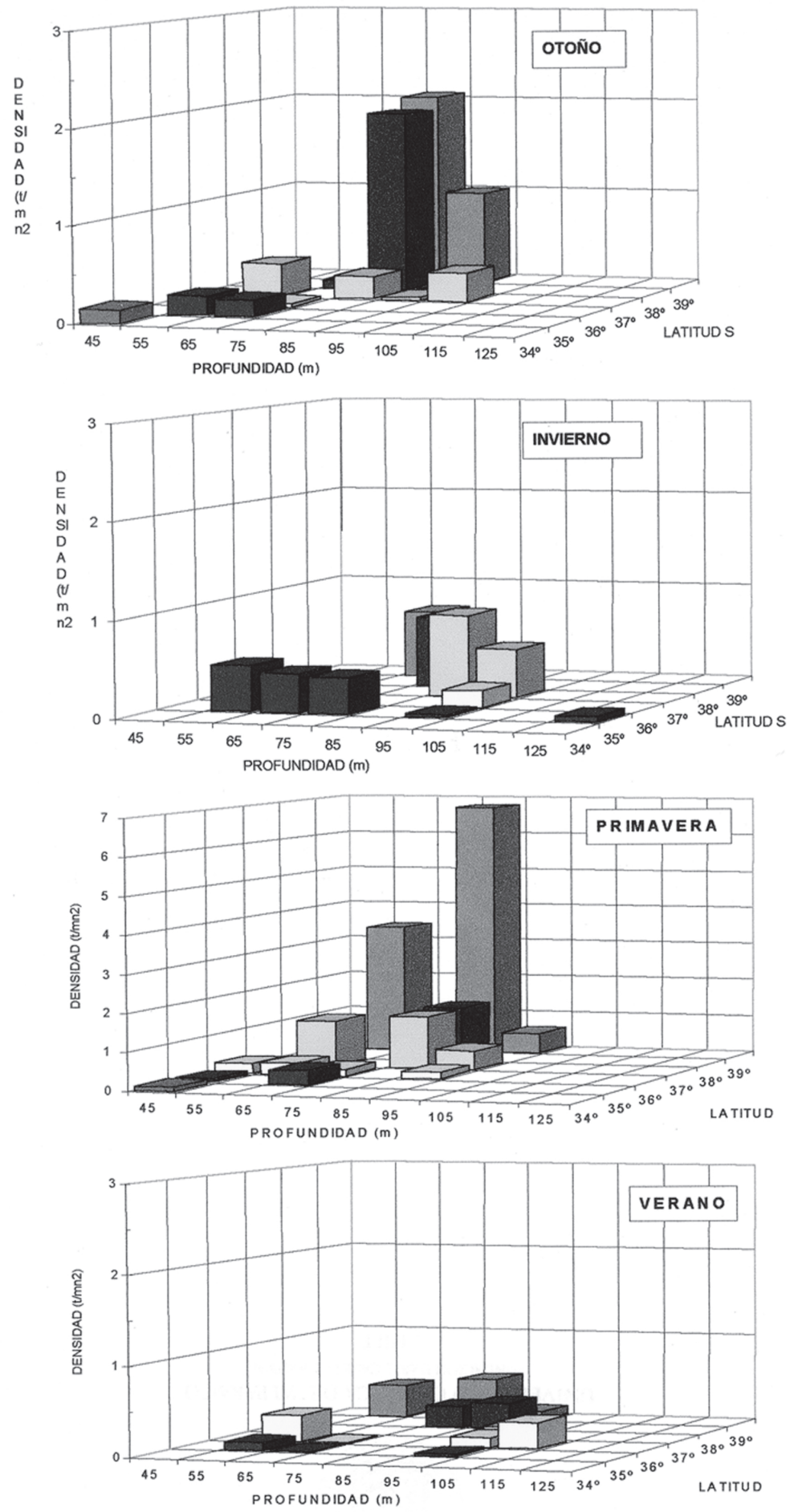

Figura 12. Variación de la densidad con la profundidad y latitud, a lo largo del año.

Figure 12. Annual density variations, according to depth and latitude.

mientos estacionales de Pseudopleuronectesamericanus, mencionó una distribución de tamaños estratificada por profundidad. Los lenguados maduros de mayor tamaño abundan en aguas más costeras en primavera y luego migran hacia aguas más profundas.

En $X$. rasile también ocurre un desplazamiento diferencial por tamaños hacia áreas menos profundas, ya que en primavera los ejemplares mayores se mueven hacia la costa y hacia el sur. Esta especie está sexualmente inactiva durante el invierno y comienza a madurar a fines de éste. En la primavera tardía, el grueso de la población se encuentra en prepuesta o en maduración avanzada y la puesta se produciría al final del año. García y Menni (1990) estudiaron el ciclo reproductivo de $X$. rasile, a partir de muestreos de desembarque del Puerto de Mar del Plata. Estos autores analizaron la variación mensual del índice gonadosomático, en ambos sexos. Los mayores valores ocurrieron entre septiembre y diciembre, alcanzando la media máxima en noviembre. A partir de estos resultados, sumados a la variación porcentual de estadios de madurez, los citados autores concluyeron que $X$. rasile comienza a madurar al inicio de primavera, completando este proceso en la segunda mitad de la misma.

Los datos de distribución de estadios de maduración gonadal en $X$. rasile, por región geográfica, indican que durante la primavera los 
ejemplares en prepuesta son más abundantes hacia el sur, en aguas someras, mientras que en el extremo norte abundan los ejemplares jóvenes. El porcentaje de hembras habitualmente superó en forma significativa al de machos. Sin embargo, ocurrieron excepciones, durante la primavera en el extremo sur del área estudiada, entre 50-75 m de profundidad, esa proporción fue de $1: 1$.

El índice de condición presentó una variación espacial en la primavera, sus mayores valores se registraron en el extremo sur del área analizada (39$40^{\circ} \mathrm{S}$ ) y entre los 76-100 m. Esta variación se puede atribuir al aumento del peso de las gónadas, que como ya fue mencionado, es significativo en esta época del año, de acuerdo con los registros de García y Menni (1990). Por otro lado, un aumento del índice de condición se debería al aumento del peso del estómago. García (1987), considerando el porcentaje de estómagos vacíos, indica que la mayor actividad alimentaria de $X$. rasile tiene lugar en otoño y primavera. No obstante, los datos de repleción estomacal presentados por la autora, demuestran que el mayor porcentaje de estómagos llenos corresponde solamente al otoño.

Las diferencias regionales en el IC, indicarían asincronía dentro de la población respecto al desarrollo de las gónadas, o bien, desplazamientos diferenciales de individuos más maduros y por sexo. Así, las gónadas de los ejemplares capturados entre los $39^{\circ}-40^{\circ} \mathrm{S}$ a profundidades mayores estarían más desarrolladas.

La variabilidad del índice de condición, dentro del área, no se puede atribuir a diferencias de tamaño. Entre los $37^{\circ}-38^{\circ} \mathrm{S}$, en el sector más próximo a la costa, se capturaron ejemplares $X$. rasile de longitud media alta, inclusive algo superior a las del estrato más sureño, pero el correspondiente índice de condición fue significativamente menor. En primavera, entre los $39^{\circ}-40^{\circ} \mathrm{S}$, las distribuciones de tamaños de machos y hembras se encuentran algo más superpuestas, posiblemente por una migración diferencial de los machos de mayor tamaño hacia esta región sureña.

De manera integral, se pueden sintetizar las características poblacionales de $X$. rasile entre los $39^{\circ}$ $40^{\circ} \mathrm{S}$ en primavera: 1) igual proporción de ambos sexos, 2) superposición de las distribuciones de tallas, 3) alto porcentaje de ejemplares maduros o en maduración avanzada en ambos sexos y 4) valores más elevados del índice de condición, como medida indirecta del grado de desarrollo de las gónadas.
Estos resultados indican que en la región más costera, ubicada al sur de Mar del Plata $\left(38^{\circ} \mathrm{S}\right)$, se localizaría el área de puesta de esta especie.

\section{Desplazamientos estacionales}

Bannister (1978) señala que la mayoría de los Pleuronectiformes muestran desplazamientos periódicos, que pueden ser de corto alcance, como es el caso de las especies endémicas o bien de mayor escala, como es el caso del "halibut" Hippoglossus hippoglossus. Esencialmente, estos movimientos poseen una fuerte componente batimétrica.

Pearcy (1978), al estudiar la distribución de algunas especies de lenguados y otras especies demersales en Oregon determinó una interacción de la profundidad con la estación del año: Glyptocephalus zachirus ("rex sole") y Microstomus pacificus ("Dover sole") fueron más abundantes a mayor profundidad en invierno que en verano, indicando movimientos estacionales batimétricos. Solea solea también migra estacionalmente entre diferentes niveles de profundidad. Este lenguado freza en el estuario del Támesis y en otoño se desplaza de aguas costeras hacia mayores profundidades (Greer Walker y Emerson, 1990).

Powler (1965) ha explicado los movimientos estacionales de Hipoglossoides platessoides, como debidos a cambios en su ciclo biológico, reproducción y alimentación en relación con condiciones ambientales (profundidad y temperatura). A inicios de verano, los individuos maduros e inmaduros se encuentran en aguas cercanas a la costa, donde se produce la puesta y permanecen en el área para alimentarse, hasta otoño, cuando migran hacia aguas más profundas. En invierno, cuando las gónadas comienzan a madurar, dejan de alimentarse. Al inicio de primavera migran hacia la costa para reproducirse y retoman la alimentación.

En $X$. rasile se observaron desplazamientos relacionados con la profundidad y también con la latitud. En el área estudiada se identificaron dos grupos de concentración, uno al norte de los $36^{\circ} \mathrm{S}$, siempre con bajísimas capturas, y otro al sur de los $37^{\circ} \mathrm{S}$. En otoño $X$. rasile fue más abundante al sur y en aguas más profundas, hacia las cuales se desplazaría para alimentarse y crecer. Durante este período, Fabré y Cousseau (1988), determinaron por análisis de borde de los otolitos, ritmo de crecimiento rápido.

En el invierno continuarían los movimientos hacia mayor profundidad y también hacia el sur. En 
esta época, si bien la mayoría de los individuos se encontraba en reposo gonadal, ya se comenzaron a observar indicios de preparación para la puesta, principalmente al sur de los $37^{\circ} \mathrm{S}$ y en aguas más profundas. Por consiguiente $X$. rasile, presentaría un comportamiento de desplazamientos estacionales relacionados, al igual que $H$. platessoides, con su ciclo biológico. Las densidades más altas de $X$. rasile de la región y del año se registraron en primavera en aguas más costeras, al norte de los $38^{\circ} \mathrm{S}$ por un lado y al sur de esta latitud por otro. Esto confirmaría que en primavera ocurre un desplazamiento de los efectivos presentes en la Zona Común de Pesca Argentino-Uruguaya hacia la costa y hacia el sur. Muy probablemente haya un ingreso de efectivos más sureños al extremo sur del área estudiada (sector comprendido entre los $39^{\circ}-40^{\circ} \mathrm{S}$ ), donde la especie se concentra para reproducirse.

En verano $X$. rasile está prácticamente ausente en los registros de la Zona Común de Pesca. Esta brusca caída de las densidades en el área seguramente está relacionada a un desplazamiento masivo después de la puesta hacia el sur. De acuerdo con Scott Becker y Chew (1983), una característica del período de "invernación" de muchos pleuronéctidos es que la alimentación se reduce en forma drástica y en algunos casos totalmente. Durante este período las gónadas comienzan a madurar usando la energía almacenada en el cuerpo. Luego, cuando los peces llegan a la costa para frezar, se encuentran en baja condición debido a la falta de alimentación y consumo energético requerido por el desarrollo gonadal y la migración.

\section{Longitud y edad de primera madurez}

Kawakami (1975), examinó ejemplares de X. rasile de tallas que variaron entre 12 y $34 \mathrm{~cm}$. Dentro de este rango de tamaños, determinó que el 50\% de los ejemplares estaban maduros a una longitud total de $18 \mathrm{~cm}$.

La longitud de primera maduración sexual estimada para $X$. rasile, en el área estudiada, fue de 20,0 $\mathrm{cm}$ en machos y de $21,2 \mathrm{~cm}$ en hembras, con dos años de edad, aproximadamente. La curva logística ajustada a los valores porcentuales de adultos, principalmente en el caso de las hembras, fue forzada hacia la izquierda, al incluir el valor cero obtenido para la clase de talla de $18 \mathrm{~cm}$. La inclusión de este valor quizás determinó una ligera subestimación del mencionado parámetro.

De acuerdo a Dryagin (1934, en Nikolsky, 1969), en las especies de peces de crecimiento relativamente rápido la madurez sexual se alcanza aproximadamente a la mitad del tamaño máximo. Si se considera que $X$. rasile es una especie de crecimiento relativamente rápido (machos, $\mathrm{k}=0,301 \pm 0,072 \mathrm{y}$ hembras, $\mathrm{k}=0,309 \pm 0,037$, Fabré, 1992) y que el tamaño máximo observado en la región bonaerense fue de $42 \mathrm{~cm}$, correspondiente a una hembra de 10 años, los valores estimados de $\mathrm{L}_{50}$ son consistentes con aquella regla general. Sobre la base de lo expuesto, puede afirmarse que los efectivos de esta especie de lenguado, procedentes de la Zona Común de Pesca Argentino-Uruguaya, entre los 50 y $100 \mathrm{~m}$ de profundidad, están constituidos esencialmente por adultos.

\section{Reclutamiento}

En la mayoría de las especies de peces, los juveniles se encuentran distribuidos en la zonas costeras, donde se alimentan de presas diferentes o de menor tamaño que los que integran la dieta de los adultos, los cuales habitualmente habitan a mayor profundidad (Cushing, 1981).

Algún tipo de segregación discreta por profundidad entre adultos y juveniles ha sido citada muy comúnmente en estudios sobre Pleuronectiformes. Entre los varios trabajos, puede mencionarse el clásico estudio de Hagerman (1952) del "Dover sole" (Microstomus pacificus), donde se demostró que los juveniles y los ejemplares de menor tamaño se encontraban en aguas poco profundas, en las llamadas áreas de crianza, segregados de los adultos.

McCraken (1963) comparó las distribuciones por tamaño de Pseudopleuronectes americanus, de cuatro diferentes áreas en el Atlántico Norte, y encontró una distribución de tallas relacionada con la profundidad, estableciendo que los peces más pequeños e inmaduros permanecen en aguas costeras durante el primer año de vida. Berghahn (1987) estudió la distribución del grupo-0 de Pleuronectes platessa, demostrando que los ejemplares entre 3,5$6,0 \mathrm{~cm}$ se localizaban entre 1 y $3 \mathrm{~m}$ de profundidad, donde no eran alcanzados por "beam trawls" o redes camaroneras. Lo mismo se observó en el Báltico respecto a Limanda limanda, cuyos ejemplares de un año de vida se concentraban entre 1 y $5 \mathrm{~m}$ (Temming, 1989). Deniel (1990), analizó la distribución de 18 especies de lenguados. La mayoría tenía como área de cría la zona intermareal o zonas cercanas a la línea de costa entre 10-30 m, mientras que los adultos habitan aguas más profundas. 
La relación positiva entre el tamaño de varias especies de peces y la profundidad refleja, fundamentalmente, aspectos de su ciclo de vida. No obstante, esta conclusión también puede ser consecuencia de problemas de muestreo, por ejemplo capturabilidad tamaño-dependiente o presión selectiva de pesca (MacPherson y Duarte, 1991).

Como ya se ha mencionado, el stock de lenguados del área analizada está compuesto por efectivos adultos. Cabe preguntarse si esto es resultado de una segregación espacial por profundidad de los juveniles, como se ha observado en otras especies de lenguados. En tal caso, puede ser que los jóvenes no estén accesibles a la flota, o bien, que los juveniles no sean vulnerables a las artes de pesca utilizadas por las embarcaciones pesqueras. No se cuenta con datos sobre la eficiencia de la red de arrastre en la captura de lenguados en Argentina, pero por los volúmenes de las capturas (alrededor de 10.000 ton/ año), comercializadas en Mar del Plata, sumado a que grandes pesquerías de lenguados en otros mares se apoyan en el empleo de redes de arrastre con portones, comparables a los aparejos utilizados en ese país, indican que estas artes de pesca serían eficientes en la explotación de este recurso demersal.

Walsh (1984), ha mencionado que las redes camaroneras son más eficientes para capturar juveniles del lenguado Gliptocephalus cynoglossus, mientras que las redes de arrastre con portones son más apropiadas para capturar adultos. Este mismo autor, replanteó la hipótesis de segregación por profundidad de adultos y juveniles, considerando datos sobre vulnerabilidad a las redes utilizadas (Walsh, 1987).

Respecto al segundo factor de importancia relacionado con el arte de pesca, en un experimento de selectividad, empleando el sistema de sobrecopo, realizado en la región costera (entre 10-50 m) de la Zona Común de Pesca Argentino-Uruguaya, muestra que no se capturaron lenguados menores de 15 $\mathrm{cm}$ de longitud total. El ingreso de reclutas a la pesquería se produce por desplazamiento hacia la región de pesca, o por cambios en el tamaño o comportamiento de los individuos durante su ciclo de vida (Ricker, 1975). Sobre la base de lo expuesto, se considera que existe una segregación espacial de los juveniles de este lenguado, por la cual no estarían accesibles a la flota pesquera comercial. Sin duda también debe haber efectos debidos a la selectividad, pero serían secundarios. $X$. rasile comienza a ingresar a la pesquería con dos años de edad. La edad más frecuente en las capturas es de tres años en los machos y cinco en las hembras. A los seis años las hembras están totalmente reclutadas al área $\mathrm{y}$ al arte y los machos a los 4 años.

Las distribuciones de edad de $X$. rasile por época del año indican la ausencia de ejemplares con dos años de edad en otoño. Hubo algunos registros en invierno, pero las mayores frecuencias se observan en primavera en aguas menos profundas.

\section{CONCLUSIONES}

Se analiza la dinámica poblacional del lenguado $X$. rasile en el sector del Atlántico Suroccidental comprendido entre $34^{\circ}-40^{\circ} \mathrm{S}$, en profundidades comprendidas entre 50-100 m, en su mayor parte dentro de la Zona Común de Pesca Argentino-Uruguaya. Las principales conclusiones a que se llegó son las siguientes.

1. En las zonas de mayor profundidad la estructura de tallas se mantuvo más estable, mientras que entre los 50-70 m de profundidad ocurrieron marcados cambios estacionales, relacionados a su vez con la latitud y con el ciclo reproductivo. En otoño las tallas medias mayores se observaron al norte del área de estudio $\left(35^{\circ}-36^{\circ} \mathrm{S}\right)$; en primavera y verano esos valores se corrieron hacia el sur. Esto demuestra que durante la primavera los ejemplares de mayor talla se desplazan hacia áreas menos profundas y hacia el sur. En otoño vuelven a aguas más profundas para alimentarse y crecer.

2. La especie está sexualmente inactiva durante el invierno y comienza a madurar a fines del mismo. En la primavera tardía, el grueso de la población se encuentra en prepuesta o en maduración avanzada y la puesta se produciría al final del año. Los porcentajes de frecuencia de los estadios de maduración gonadal, considerados regionalmente, indican que en primavera los ejemplares en prepuesta son más abundantes hacia el sur, en aguas someras, mientras que en el extremo norte abundan los ejemplares inmaduros.

3. El índice de condición presentó una variación espacial en primavera, sus mayores valores se registraron en el extremo sur del área analizada ( $39^{\circ}$ $40^{\circ} \mathrm{S}$ ) y entre los 76-100 m. Esta variación puede atribuirse al aumento del peso de las gónadas.

4. La longitud de primera maduración sexual estimada fue de $20 \mathrm{~cm}$ para los machos y de $21 \mathrm{~cm}$ para las hembras, con 1,29 y 1,94 años respectiva- 
mente. La curva logística ajustada a los valores porcentuales de adultos, principalmente en el caso de las hembras, fue forzada hacia la izquierda, al incluir el valor cero obtenido para la clase de talla de $18 \mathrm{~cm}$. La inclusión de este valor quizás determinó una ligera subestimación del mencionado parámetro. Sobre la base de la distribución de tallas observada, puede afirmarse que los efectivos de $X$. rasile estudiados están constituidos esencialmente por adultos.

5. $X$. rasile comienza a ingresar a la pesquería con dos años de edad. La edad más frecuente en las capturas es de tres años en los machos y cinco en las hembras. A los seis años las hembras están totalmente reclutadas al área y al arte, y los machos a los 4 años. Las distribuciones de edad de $X$. rasile por época del año indican la ausencia de ejemplares con dos años de edad en otoño. Hubo algunos registros en invierno, pero las mayores frecuencias se observan en primavera, en aguas menos profundas.

\section{AGRADECIMIENTOS}

Las autoras quieren expresar su sincero agradecimiento a la Comisión Técnica Mixta Argentino-Uruguaya, especialmente al Lic. Héctor Otero (Pos mortem) por permitir el uso de los datos. Muy especialmente al INIDEP por el continuo apoyo ofrecido durante el desarrollo de este trabajo y a los investigadores del ex laboratorio de Biología Pesquera del INIDEP, especialmente al Dr. Jorge Hansen por su valioso asesoramiento.

\section{REFERENCIAS}

Bannister, B.C. 1978. North sea plaice. The biology of flatfishes. En: J.A. Gulland (ed.). Fish Population Dynamics. John Wiley \& Sons, Toronto, pp. 242281.

Berghahn, R. 1987. Effects of tidal migration on growth of 0-group plaice (Pleuronectes platessa L.) in the North Frisian Wadden Sea. Meeresforsch., 31: 209-226.

Cousseau, M.B. y J.M. Diaz de Astarloa. 1991. Investigaciones sobre dos categorías específicas Paralichthys bicyclophorus y Paralichthys patagonicus. Pub. Com. Téc. Mix. Fr. Mar., 8: 5160.
Cushing, D.H. 1981. Fisheries biology. A study in population dynamics. The University of Wisconsin Press, England, 295 pp.

Dell'Arciprete, P., H.E. Christiansen y J.M. Diaz de Astarloa. 1987. Observaciones sobre el ciclo reproductivo del mero, Acanthistius brasilianus (Serranidae, Pisces). Rev. Inv. Des. Pesq., Mar del Plata, Argentina, 7: 67-84.

Deniel, C. 1990. Comparative study of growth of flatfishes on the west coast of Brittany. J. Fish Biol., 37: 149-166.

Fabré, N.N. 1992. Análisis de la distribución y dinámica poblacional de lenguados de la Provincia de Buenos Aires (Pisces, Bothidae). Tesis Doctoral, Univ. Nacional de Mar del Plata, Argentina, 266 pp.

Fabré, N.N. y J. M. Diaz de Astarloa. 1996. Pleuronectiformes de importancia comercial en el sector del Atlántico Sudoccidental comprendido entre los 34 $30^{\prime}$ y $55^{\circ} \mathrm{S}$. Distribución y consideraciones sobre la pesca. Rev. Inv. Des. Pesq., Mar del Plata, Argentina, 10: 45-55.

Fabré, N.N. y M.B. Cousseau. 1988. Resultados de las primeras observaciones sobre la edad y el crecimiento en el lenguado Xystreurys rasile. Pub. Com. Téc. Mix. Fr. Mar., 4: 107-116.

García, M.L. 1987. Régimen alimentario de Xystreurys rasile (Jordan, 1890) (Teleostei, Bothidae). Inv. Pesq., Barcelona, 51: 155-166.

García M.L. y R.C. Menni. 1990. Studies on Argentine Pleuronectifomes V: Morphometrics and other biological aspects of Xystreurys rasile (Bothidae, Paralichthyinae). Gayana (Zool.), 54(34): 67-77.

Greer Walker, M. y L. Emerson. 1990. The seasonal migration of sole (Solea solea) through the Dover strait. Neth. J. Sea Res., 25(3): 417-422.

Gulland, J.A. 1983. Fish stock assessment. A manual of basic methods. John Wiley \& Sons, New York, $223 \mathrm{pp}$.

Hagerman, F.B. 1952. The biology of the Dover sole, Microstomus pacificus (Lockington). U.S. Fish Bull., 85: 1-51.

Kawakami, E. 1975. Alimentação de Pleuronectiformes (Análise comparativa e bionomia). Dissertação Mestrado. Instituto Oceanográfico, USP, São Paulo, Brasil, 150 pp. 
McCracken, F.C. 1963. Seasonal movement of the winter flounder Pseudopleuronectes americanus (Walbaum), on the Atlantic Coast. J. Fish. Res. Bd. Can., 20(2): 552-585.

MacPherson, E. y C.M. Duarte. 1991. Bathymetric trends in demersal fish size: is there a general relationship?. Mar. Ecol. Prog. Ser., 71: 103-112.

Nikolsky, G.V. 1969. Theory of fish population dynamics as the biological background for rational exploitation and management of fishery resources. Oliver \& Boyd, Edinburgh, 323 pp.

Pearcy, W.G. 1978. Distribution and abundance of small flatfishes and other demersal fishes in a region of diverse sediments and bathymetry off Oregon. U.S.Fish. Bull., 76(3): 629-640.

Powler, P.M. 1965. Life history and ecology of american plaice (Hippoglossoides platessoides F.) in the Magdalen shallows. J. Fish. Res. Bd. Can., 22(2): 565-597.

Ricker, W.E. 1975. Computation and interpretation of biological statistics of fish populations. Bull. Fish. Res. Bd. Can., 191: 1-382.

Scott Becker, D. y K.K. Chew. 1983. Fish-benthos coupling in sewage enriched marine environments. Final Report. NOAA Project ( ${ }^{\circ}$ NA 80 RAD
00050). School of Fisheries, Seattle, Washington, $78 \mathrm{pp}$.

Sokal, R.R. y F.J. Rohlf. 1981. Biometry. The principles and practice of statistical in biological research. W.H. Freeman and Company, New York, $859 \mathrm{pp}$.

Sparre, P. y S.C. Venema. 1997. Introducción a la evaluación de recursos pesqueros tropicales. Parte 1. Manual FAO, Doc. Téc. de Pesca No 306.1 Rev. 2, $420 \mathrm{pp}$.

Steel, R.G. y J.H. Torrie. 1985. Bioestadística. Principios y procedimentos. McGraw-Hill, Bogotá, 527 pp.

Temming, A. 1989. Migration and mixing of dab (Limanda limanda) in the Baltic. Rapp. P. v. Réun. Cons. Int. Explor. Mer, 190: 25-38.

Walsh, S.J. 1984. Relative efficiency ot two bottom trawls in catching juvenile and commercial sized flatfishes in the Gulf of St. Lawrence. J. Northw. Atl. Fish Sci., 5: 181-188.

Walsh, S.J. 1987. Habitat partitioning by size in witch flounder Glyptocephalus cynoglossus: a reevaluation with additional data and adjustments for gear selectivity. U.S. Fish. Bull., 85(1): 147153. 
